\title{
SANIDAD PREVENTIVA Y SALUD PUBLICA EN EL MARCO DE LA ACTUAL ADMINISTRACION SANITARIA ESPAÑOLA
}

\author{
POR \\ manuel Rebollo Puig \\ Doctor en Derecho. Profesor de Derecho Administrativo de la Universidad \\ de Córdoba
}

SUMARIO: 1. CRITERIO de delimitación de La SANIDAd PÚBLICA. - 2. SANIDAd PREVENTIVA Y CURATIVA. - 3. LA SANIDAD LIBERAL COMO ACTIVIDAD EXCLUSIVAMENTE PREVENTIVA. 4. LA SALUD PÚBLICA. -5. El INTENTO DE COMPATIBILIZAR LA ATENCION PÚBLICA A LA SALUD INDIVIDUAL CON EL MANTENIMIENTO DEL AMBITO ESTRICTO DE LA SANIDAD LIBERAL. 6 . LAS BASES DE LA NUEVA SANIDAD: EL OBJETIVO DE LA SANIDAD INTEGRAL. -7. LA CONFIGURACIÓN DE la SaNidad y la protección de la salud en la Constitución. El derecho a la salud. 8. La SANIDAD EN LA ACTUAL LEGISLACIÓN SANITARIA. -9. IMPORTANCIA ACTUAL DE LA SANIDAD PREVENTIVA. - 10 . SaNidad PREVENTIVA Y SALUD PÚBLICA EN La CONSTITUCIÓN Y EN LA RECIENTE LEGISLACIÓN SANITARIA.

\section{CRITERIO DE DELIMITACION DE LA SANIDAD PUBLICA}

La primera dificultad para exponer un panorama general de la sanidad pública es su misma evolución en la que se han ido alterando sus aspectos esenciales. Cierto es que, pese a lo variable $y$ contingente del contenido $y$ fines de la labor administrativa -siempre dependiente de los juicios políticos y de las distintas respuestas sobre los fines mismos del Estado (1)-puede afirmarse que en todo momento histórico y en toda organización pública, por elemental que sea, se han identificado como intereses comunitarios y se han asumido por los Poderes públicos ciertos aspectos de lo afectante a la salud (2). Pero si ello puede considerarse efectivamente como una constante histórica, no ocurre lo mismo con la

(1) Así, MERKL decía que «la diversidad de contenidos de la acción administrativa es mucho mayor que la variedad de formas... Además, dependen en mayor grado de los cambios de tiempo $y$ de lugar... El espíritu del tiempo y del pueblo se vacian en forma característica en los contenidos administrativos. Como que son los termómetros de la cultura nacional, indicadores de las orientaciones de las dominantes políticas..." A. MERKL: Teoría General del Derecho Administrativo, México, 1980, p. 295.

(2) R. MARTIN MATEO: "Ordenación pública del sector salud», señala igualmente, que «la preocupación pública por los problemas sanitarios constituye una constante histórica; en todos los momentos de la historia pueden detectarse en tal materia la sustantivización de intereses comunitarios y su atendimiento por las respectivas organizaciones políticas por rudimentarias que fuesen, llegándose en algunos momentos a un amplio despliegue de iniciativas públicas que, como en el caso de la civilización romana, cubrían importantes aspectos del saneamiento de las poblaciones y la asistencia a grupos relativamente extensos» en RAP. núm. 84, septiembrediciembre, p. 371. 
extensión de estos intereses sanitarios de la comunidad, ni el grado de asunción de la organización política; tampoco han sido iguales los medios jurídicos, ni la justificación de esta actuación pública. Por el contrario, la extensión de ello y el mismo concepto de sanidad pública han experimentado continuas transformaciones como resultado de las nuevas concepciones dominantes o de específicos problemas sociales cuyo atendimiento no permitía demoras. Ello, unido a operarse sobre organizaciones administrativas preexistentes que, en principio, respondían a principio o problemas abandonados o superados, ha determinado generalmente un perfil de la šanidad pública no fácilmente reconducible a esquemas generales y a construcciones acabadas. También la situación actual española, pese a presentarse como un sistema sanitario de nueva planta, ofrece en realidad estas características manifestándose, por una parte, como el resultado de una lenta evolución y, por otra, como un resultado inacabado y tendencialmente expansivo.

En realidad, ello no constituye un carácter peculiar de la sanidad pública calificable -como expresa Villar Palasí- toda la «Administración como fenómeno variable» (3). Pero en la sanidad ello se hace especialmente patente, como ha destacado Morell Ocaña:

«... La Administración no aparece en la vida real como un reflejo de un esquema teórico sino como un producto histórico formado por aluvión... no admite fácilmente construcciones totales de nueva planta que rompan totalmente con el pasado cada vez que cambia el horizonte social en que estaba situada...

No hay, seguramente, un ejemplo mejor de lo que se afirma que el cuadro institucional a través del cual la Administración se ocupa hoy del cuidado de la salud de sus ciudadanos; cuadro compuesto de instituciones cuyo nacimiento ha sido la condensación final de una serie de factores políticos, sociales y económicos, en cada caso diversos, que han progresado en forma de aluvión, mediante un sistema puramente aditivo y que pugna por adaptarse a la peculiar problemática de nuestros días» (4).

Sirva lo anterior como justificación del punto de vista histórico que, sin pretender tampoco describir completamente la evolución de esta actividad administrativa, adoptaremos para configurar la

(3) J. L. VILLAR PALASi: Curso de Derecho Administrativo, t. I, Madrid, 1972, pp. 56 y ss.

(4) L. MORELL OCAÑA: "Evolución y configuración actual de la actividad administrativa. sanitaria», en RAP núm. 63, septiembre-diciembre 1970, pp. 131 a 134, passim. 
sanidad pública o algunos de sus aspectos más relevantes. Sirva asimismo, para descartar cualquier intento de definirla en base a las concretas tareas relativas a la salud de las que en cada momento se ha hecho cargo la Administración.

Anticipada ya la distinta amplitud con que la Administración ha asumido tareas relacionadas con la salud, se comprenderá que no es posible, o al menos no es útil, acotar esta actividad pública en base a una descripción más o menos detallada de sus distintas funciones (5). Si de un concepto genérico de sanidad (que englobe a la pública y a la privada) puede hablarse, una parte es ajena a la Administración; se realiza por los propios individuos interesados o por los profesionales implicados directamente en las funciones sanitarias. La línea divisoria entre esta actividad sanitaria privada y la que es asumida por la Administración -sin entrar en los campos de coincidencia- cambia. También, en función de los avances y descubrimientos científicos y técnicos, el campo de actividades sanitaria, en general, y de la sanidad pública, en particular aumenta. Pero ello; obviamente, no puede ser óbice para aislar un concepto de sanidad, ni para encuadrar en él un conjunto de actuaciones administrativas concretas. Sencillamente, hay que seguir un camino distinto para delimitar la Sanidad pública.

Tampoco el criterio orgánico supone, de por sí, base suficiente para definir la actividad administrativa sanitaria. Las objeciones reiteradas por la doctrina, con carácter general, a la estructuración del Derecho Administrativo en base a la organización (6) se ven aqui reforzadas. Por una parte, ha existido una dispersión competencial notoria en esta materia, las más de las veces asistemática e injustificada, pero, en buena medida, insalvable. Por otra, se hace especialmente visible que la organización diferenciada es la consecuencia, y no la causa, de una función diferenciada, y que ésta ha de ser aislada con independencia de aquélla. Es decir, la organiza-

(5) En este sentido, ha dicho MOUNTIN que la naturaleza progresiva de la salud pública hace difícil cualquier definición restringida de las funciones y responsabilidades de los departamentos de salubridad. Citado por M. MARTín GONZÁLEZ en Sanidad pública: concepto y encuadramiento, Madrid, 1970, p. 655, nota 994. En el mismo sentido, afirma YUSTE GRIJALVA que «existe un verdadero peligro al intentar circunscribir algo en continuo movimiento $y$ en ininterrumpido desarrollo», y añade que tal planteamiento erróneo "ha llevado a identificar la sanidad con las funciones y organización de la Dirección General que se adjetiviza con ese nombre), F. J. YUSTE GRIJALVA: "Salud pública y desarrollo», Documentación Administrativa, núm. 114, junio, 1967, p. 27

(6) Se ha señalado así que «la caótica distribución competencial y la variedad de funciones... encomendadas a cada complejo orgánico» hace «muy difícil llegar al conocimiento de la verdadera naturaleza y características de cada una. También se niega su aptitud encuadradora de las diversas manifestaciones del actuar administrativo, porque el aparato montado para su desarrollo de una actividad administrativa específica es señal de que tal actividad diferenciada existe; pero es una consecuencia, no la causa o razón de la diferenciación», M. MARTín GONZÁlez: Sanidad pública..., op. cit., p. 811. 
ción se establece en base a aislar una determinada actividad como sanidad. Si, a su vez, ésta la definiésemos con criterios orgánicos convertiríamos el problema en una tautalogía. Sin embargo, no creemos que pueda prescindirse absolutamente de tal criterio orgánico, del que posteriormente tendremos que hacer uso.

Es generalmente un criterio teleológico el seguido por la doctrina para conceptuar la sanidad pública. Explícita o implícitamente, es el fin de ciertas actividades administrativas lo que se considera determinante para su inclusión en este sector (7). En base a ello, y en una primera aproximación, es fácil afirmar que el fin consiste en proteger la salud. Pero, inmediatamente, se hacen necesarias mayores precisiones. ¿Cualquier tema que afecte a la salud interesa a la sanidad? ¿Qué salud y en qué medida la protege la sanidad pública? ¿La salud individual o la salud pública?

\section{SANIDAD PREVENTIVA Y SANIDAD CURATIVA}

La atención a la salud comprende dos niveles perfectamente diferenciables:

Por una parte, puede pretenderse tan sólo crear las condiciones sociales adecuadas para la conservación de la salud: para que las existencias individuales y sus actividades, o la misma naturaleza, no alteren negativamente tales condiciones; para que exista un estado general de la sociedad en que sea posible la salud de sus miembros. Trata de proteger contra los peligros para la salud derivados de la vida en sociedad. No se pretende curar al individuo, $\mathrm{ni}$-hablando estrictamente- evitar que caiga enfermo, sino tan sólo que no vea afectada negativamente su salud por las condiciones sociales.

De otra, la actividad sanitaria puede atender a la salud de cada uno de los individuos, aisladamente considerados, sin atención alguna a que tenga o no relevancia social. En este nivel puede atender sus enfermedades haciéndose cargo de su curación mediante asistencia médica, hospitalaria o farmacéutica; puede, incluso, pretender que no caiga enfermo mediante campañas educativas, revisiones periódicas o medicación adecuada; puede,

(7) Con carácter general, defiende y expone este criterio G. ZANOBINI: «El único criterio de partición de aquél, completamente empírico, de examinar las diversas actividades según los fines a que se dirigen, prescindiendo de cualquier clasificación o agrupamiento.» En base a ello llega a aislar la sanidad. Corso de Diritto Amministrativo, Milán, 1959, vol. V. pp. 9 y 10

En nuestra doctrina, y específicamente refiriéndose a la sanidad, utilizan un criterio teológico M. MARTín GONZÁLEZ: Sanidad pública: concepto y encuadramiento, Madrid, 1970, pp. 977 y SS., y S. MUÑOZ MACHADO: La sanidad pública en España (evolución histórica y situación actual), Madrid, 1975, p. 19 
por último, procurar que los efectos de la enfermedad sean lo menos perjudiciales para el individuo (8).

Todas estas posibles actividades y funciones tienen por finalidad la protección de la salud; todas podrían calificarse como actividades sanitarias $y$, de hecho, son objeto de las distintas ciencias y profesiones sanitarias. Pero no todas se han considerado históricamente asumibles por la Administración, ni integrantes del contenido de la sanidad pública. Precisamente, la línea establecida entre los dos niveles aludidos ha constituido la divisoria básica a los efectos de perfilar la finalidad de la actividad pública sanitaria. Así, pues, tanto desde una perspectiva histórica, como desde la de la realidad jurídica de la sanidad actual, es esencial distinguir entre salud pública y salud individual, y la actividad administrativa que se ocupa de una y otra (9).

A la distinción realizada se alude comúnmente con la clasificación de sanidad preventiva y curativa (o represiva, asistencial o reparadora). Así, Lessona distingue entre vigilancia higiénica y asistencia sanitaria. La primera corresponde, dice, a toda la función preventiva en la que incluye el conjunto de normas encaminadas a la profilaxis de las enfermedades y a su supresión en cuanto su existencia constituye un peligro social. La asistencia sanitaria, por contra, comprende la acción curativa e integra el conjunto de medidas encaminadas a que, cuantos quieran, puedan ser curados sin atender a su situación económica o social (10). Con parecido significado habla Muñoz Machado de sanidad preventiva y asistencial: "Denominaremos sanidad preventiva a toda actuación pública que se refiera a la tutela de la salud de la colectividad en su conjunto, y sanidad asistencial, a la destinada a atender a los problemas sanitarios individuales» (11): La distinción entre estos dos aspectos de la sanidad es evidente $y$ ha sido puesta de manifiesto por la doctrina (12). Los términos empleados para

(8) Claramente lo expresa E. BORRA JO DACRUZ: "... en la salud hay dos dimensiones, una individual y otra colectiva, y asi a las condiciones que se pueden apreciar en el hombre a su constitución psicofísica aparecen las condiciones del medio en el que el hombre se desenvuelve, 10 quiera o no lo quiera, con todas sus implicaciones de medio ambiente de la vida personal y familiar (vivienda), de trabajo, vecinal, escolar, urbano o rural, etc.», "El derecho a la asistencia sanitaria de la Seguridad Socialı, en / Congreso Nacional de Derecho del Trabajo y de la Seguridad Social, Madrid, 1981, vol. 2, p. 532.

(9) Vid. infra, apartado 10.

(10) S. LeSSONA: Tratatto di Diritto Sanitario, Roma, 1914, pp. 37 y 38.

(11) S. MUÑOZ MACHADO: La sanidad..., op. cit., p. 19:

(12) Incluso ha encontrado algún reflejo constitucional. Asi ocurre en Portugal, cuya Constitución establece: «Incumbe prioritariamente al Estado, con el fin de asegurar el derecho a la protección de la salud: a) garantizar el acceso de todos los ciudadanos... a los cuidados de la medicina preventiva, curativa y de rehabilitación...» (art. 64.3). También en nuestra Constitución, entendemos; estos conceptos han encontrado cierta consagración, especialmente la sanidad preventiva. Vid. infra, apartado B del epígrafe II de este mismo capitulo.

REVISTA DE ESTUDIOS.-5 
referir tal realidad son, sin embargo, equívocos y requieren algunas precisiones.

Es correcto denominar sanidad preventiva a aquella que tiene por finalidad atender a la salud de la colectividad, y en este sentido utilizaremos nosotros la expresión. Pero no pueden entenderse tales términos en el sentido de incluir todo acto de naturaleza preventiva y sólo a éstos. Si así se hiciera, habria que englobar en tal concepto, por ejemplo, un chequeo médico o cualquier operación encaminada a evitar la manifestación o agravación de cualquier insuficiencia o defecto orgánico potencialmente peligroso para el individuo, cuando es evidente que para nada afecta a la salud de los demás, a la salud de la colectividad. Por el contrario, habría de excluirse cualquier actividad dirigida a combatir la epidemia ya desatada y la hospitalización de los enfermos contagiosos, aun cuando con ello normalmente se pretende no tanto la curación de los enfermos afectados, como la no propagación a los demás de la enfermedad, es decir, la salud de la colectividad. De hecho, en este otro sentido se ha definido también la sanidad preventiva (13), sin atender en absoluto al bien, individual o colectivo, cuya protección constituye la finalidad de la actuación.

Frente a ello, resulta de interés reparar cómo Lessona, según ya hemos dicho, incluye en la función preventiva la represión de las enfermedades en cuanto su existencia constituye un peligro social. La aparente contradicción de los términos queda salvada y el sentido de la expresión sanidad preventiva se hace comprensible, desde una perspectiva más general que la del contenido (preventivo, curativo o asistencial) de cada uno de los actos que la integran. Hay que atender a la finalidad típica de la acción pública en su conjunto $y$, desde este punto de vista, la salud de la colectividad no puede tutelarse más que con actuaciones preventivas. Ello es algo constantemente puesto de manifiesto por los autores cuando contemplan la sanidad desde este punto de vista de la colectividad. Son expresivas a este respecto afirmaciones como la de Colmeiro, para quien la sanidad pública «supone una actividad esencialmente previsora» (14), o la de Bortolotto, señalando que la

(13) Así, H. S. MUSTARD y E. L. STEBINS afirman que «la medicina preventiva puede ser considerada como el cuerpo de conocimientos y prácticas que contribuyen al mantenimiento de la salud y a la prevención de la enfermedad, ya sea en el individuo o en la colectividad". Introducción a la salud pública, traducción española A. Temoche Carolina, México, 1965, p. 15.

Tambien R. ALESSI incluye en la prevención de medidas que sólo atienden al mantenimiento de la salud individual y en la sanidad curativa cualquier acción contra la enfermedad ya desatada, aunque lo que se pretenda sea evitar su propagación y defender a la colectividad. Citado por $\mathbf{M}$. MARTín GONZÁlEZ: Sanidad..., op. cit., p. 355.

(14) M. COLMEIRO: Derecho Adrministrativo Español, T. I, Madrid, 1865, p. 306 
sanidad está constituida por «disposiciones de carácter preventivo dirigidas a la conservación y defensa de la salud...» (15).

Aún habría que añadir que a la sanidad preventiva no le es ajena la asistencia sanitaria. Por el contrario, interviene en ella, además de por la prestación de asistencia profiláctica, estableciendo las condiciones para el ejercicio de las profesiones sanitarias, de los hospitales, etc., porque todo ello determina el conjunto de condiciones sanitarias sociales que hacen posible la salud de cada uno de los individuos (16). Ahora bien, no asume ella misma la asistencia sanitaria de las enfermedades socialmente irrelevantes.

Parecidas observaciones pueden hacerse a la identificación de la sanidad curativa, asistencial o represiva con aquella que se ocupa de la salud individual sin atender a la relevancia social, pues igualmente se cura al enfermo infeccioso, o se reprime la epidemia declarada o se presta asistencia al vacunar. (17), aunque todo ello se haga atendiendo no a la salud de los individuos concretos afectados, sino a la comunidad en su conjunto.

Así, si inicialmente dijimos que el fin de la sanidad pública es proteger la salud, podemos precisar ahora que, históricamente, la sanidad pública se ha limitado a aspectos parciales de ese fin genérico, que éste, sólo en parte, ha sido asumido por los poderes públicos, que sólo el primer nivel, al que nos-referimos anteriormente -es decir, el que atiende a las condiciones sociales adecuadas para hacer posible la salud, a la salud de la colectividad-, ha constituido fin de la Administración sanitaria. Ello sin perjuicio de reconocer, como posteriormente se explicará, que la Beneficencia, primero, y la Seguridad Social, después, atendieron las necesida-

(15) A. Bortolotto: "Sanita pública», Enciclopedia del Diritto Penale italiano, vol. XIII, p. 515.

(16) Esta finalidad de mantener las condiciones que hacen posible la salud de cada individuo es la determınar'e en estas intervenciones. Ello no impide reconocer la concurrencia de otros fines. Así se ha dicho que «los profesionales sanitarios están reglamentados en favor del público y en favor de los mismos profesionales, pues se pretende la defensa de los intereses profesionales...». S. ALVAREZ GENDiN Y. BLANCO: "Régimen administrativo de la sanidad», en Estudios en homenaje al profesor López Rodó, Madrid, 1972, II, p. 426.

(17) La doctrina no ha dudado al calificar estas actuaciones como de sanidad preventiva y no asistencial. Así, ZANOBINI al referirse a la distinción que formula como "acción preventiva» y "acción repadora", precisa que la acción preventiva incluye prestaciones asistenciales encaminadas a fortalecer a las personas contra ciertas enfermedades, Corso de Diritto Administrativo. op. cit., vol. V. pp. 152 y 153. MUÑOZ MACHADO que califica de asistenciales a «aquellas actuaciones administrativas que vayan destinadas a la protección de la salud del individuo aisladamente considerado, es decir, atendiendo sólo a sus peculiares necesidades con independencia de que su enfermedad pueda o no alterar a la comunidad en que vivel, aclara que "en el extenso panorama de técnicas que son propias de la sanidad preventiva se pueden detectar algunas que tienen urı marcado carácter asistencial; sin embargo, este dato no debe servir para descalificarla como oreventiva si, teleológicamente, se inserta en un conjunto que se instrumenta con destino a prccurar la eliminación de lo que puede ser una amenaza para la salud colectivan. S. MUÑOZ MACHADO: La sanidad pública en Éspaña (evolución histórica y situación actual), Madrid, 1975, pp. 19-20. 
des de asistencia sanitaria de extensísimas capas de la población, supliendo las insuficiencias de lo que con propiedad podía calificarse como Administración sanitaria, únicamente preocupada de la prevención y salud pública, salvo puntuales excepciones que sólo en este siglo cobran verdadera relevancia. Prescindiendo de antecedentes más lejanos -cuyo estudio a los efectos que nos ocupan es de escasa utilidad-, es ello una característica básica y reiteradamente señalada de la Administración sanitaria liberal.

\section{LA SANIDAD LIBERAL COMO ACTIVIDAD EXCLUSIVAMENTE PREVENTIVA}

Los principios básicos de la sanidad liberal no son sino concreción, traducción en este sector, de los generales que inspiran toda la configuración de la Administración y sus relaciones con la sociedad y los administrados. Con independencia, ahora, de su justificación teórica y formulación doctrinal, interesa dejar constancia de la configuración esencialmente preventiva $y$, consecuentemente, tan abstencionista como es posible de la Administración en materia de salud. Preciso es aclarar, sin embargo, que ha de atenderse fundamentalmente a las funciones prestadas por la Administración local en la que se encuentra concentrado el desarrollo de las acciones sanitarias públicas y la raíz de la evolución posterior. El Estado, dejando a salvo lo relativo a sanidad exterior, no cuenta con una organización y estructura capaz de asumir las acciones que la defensa de la salud impone. Sólo a partir del despliegue de la Administración periférica, que se produce en España desde 1833, concurren las condiciones mínimas, y aún asi su efectividad real y virtualidad práctica inicial, lo matizan intensamente, para que la Administración del Estado asuma un papel relevante en lo atinente a la salud. No puede perderse de vista este forzado protagonismo de la Administración local a la hora de configurar y valorar nuestra sanidad decimonónica, que queda absolutamente desdibujada si se centra la perspectiva en los servicios estatales.

Aún así, al margen dejaremos lo que propiamente podría incluirse en la tradicional policía de mercado o policía de subsistencias que constituía núcleo esencial de las competencias municipales de intervención en materia de alimentos y que influye decisivamente en la configuración posterior de la actividad administrativa objeto de estudio. Sin negar su conexión con los aspectos sanitarios, la acción administrativa que con propiedad puede incluirse bajo tal título responde a finalidades distintas reconduci- 
bles a la idea de honradez comercial, leal concurrencia en el mercado o lucha contra el fraude.

La Constitución de 1812, si bien no aludía con carácter general al tema que nos ocupa, es expresiva en cuanto a las competencias de los Ayuntamientos y Diputaciones en la materia: Sólo upolicía de salubridad", además de intervención en Beneficencia (18). Confirma lo anterior el Reglamento de 23 de julio de 1812 (19) y, sobre todo, la Instrucción para el gobierno económico y político de las Provincias de 23 de junio de 1813 cuyo artículo I señalaba: «Estando a cargo de los Ayuntamientos de los pueblos la policía de salubridad y comodidad, deberán cuidar de la limpieza de las calles, mercados, plazas públicas y la de los hospitales, cárceles y casas de caridad o beneficencia: velar sobre la calidad de los alimentos de toda clase: cuidar de que en cada pueblo haya cementerio convenientemente situado: cuidar asimiso de la desecación, o bien de dar curso a las aguas estancadas o insalubres: y por último, de remover todo lo que en el pueblo o en su término pueda alterar la salud pública o la de los ganados." Junto a ello, y además de la reglamentación de las profesiones sanitarias, la lucha contra las enfermedades epidémicas o contagiosas (atribuida por la misma Instrucción al Jefe Político, art. XXIII del cap. III) y el sector de la sanidad exterior, constituian prácticamente el entero panorama de la sanidad pública (20).

La Instrucción para el gobierno económico y político de las provincias de 3 de febrero de 1823 sí supuso, por el contrario, una excepción destacable (21), aunque más teórica que real, a la

(18) Según su articulo 321 , correspondía a los Ayuntamientos: "1. ${ }^{\circ}$ La policía de salubridad y comodidad... $6 .^{\circ}$ Cuidar de los hospitales, hospicios y demás establecimientos de beneficencia...) El artículo 325 encomendaba a las Diputaciones, en su apartado $8^{\circ}$, "cuidar de que los establecimientos piadosos y de beneficencia llenen su respectivo objeto, proponiendo al Gobierno las reglas que estimen conducentes para la reforma de los abusos que observaren". Vid. S. MUÑOZ MACHADO: "Reflexiones sobre la reforma de la sanidad local», Documentación Administrativa núm. 163, enero-febrero 1975, pp. 48 a 52

(19) Son sus artículos 16 y 17 los que se ocupan de las competencias en la materia "centrando su atención en el servicio sanitario interior y exterior y en la dirección y vigilancia de las profesiones médicas», como señala L. MORELL OCAÑA: "La evolución y configuración actual de la actividad administrativa sanitaria», en RAP núm. 63, septiembre-diciembre 1970, p. 139.

(20) Comentando el citado artículo 1 de la Instrucción, dice MUÑOZ MACHADO que «en este artículo quedaba totalmente descrito el contenido posible de la actividad administrativa en materia de sanidad en aquella época...n, op. cit., p. 77.

En la misma línea se desenvolvía el proyecto de Código Sanitario de 1822, cuyo análisis omitimos en el texto, ya que fue finalmente rechazado. Sobre el mismo tema, véase M. y J. L. PESET: Muerte en España (política y sociedad entre la peste y el cólera), Madrid, 1972, pp. 195 y ss.; S. MUÑOZ MACHADO: Op. cit., pp. 85 y ss.

(21) Su importancia deriva del mismo valor reconocido a esta Instrucción de 1823, que se convirtió, durante gran parte del siglo XIX, en el modelo liberal de Administración local. Así, afirman S. MARTín-RETORTILLO BAQUER y E. ARGULLOL MURGADAS que constituyó "un precedente continuamente reclamado más tarde por quienes aspiraban a una mayor participación 
exclusión absoluta de la sanidad asistencial pues, si bien reiteraba el artículo I de la Instrucción de 1813, establecía en su artículo 12 que «Deben procurar los Ayuntamientos que haya facultativo... por la asistencia de los pobres, sin perjuicio de que, si los fondos públicos lo pueden sufrir, se extienda también la dotación a la asistencia a todos los vecinos...» Como ha puesto de manifiesto Muñoz Machado «es ésta la primera manifestación, aunque su contenido sea parcial, de la asunción por la Administración del cuidado de la salud individual» extendiéndose a toda la población y no tan sólo a los indigentes (22). Pero, en cualquier caso, no tuvo efectividad real (23) y desapareció en la siguiente legislación de régimen local. Este período responde, pues, en la práctica, plenamente a una sanidad limitada al aspecto preventivo (24).

La Ley de 28 de noviembre de 1855 del Servicio General de Sanidad, nuestra primera Ley específicamente sobre este sector, no altera la situación; mas bien puede decirse que la ordena, sistematiza $y$, en suma, consagra: si bien es fundamentalmente una norma de organización, se observa que en ningún momento se incluyen servicios que pudieran considerarse de sanidad asistencial (25), desapareciendo ya totalmente la referencia a

popular y a una renovación de la vida de las Corporaciones Locales», en la obra colectiva Descentralización administrativa $y$ organización política, dirigida por S. MARTIN-RETORTILLO BAQUER, tomo I, Aproximación histórica (1812-1931), Madrid, 1973, p. 82.

De hecho, aunque discontinua, tuvo la Instrucción de 1823 una vigencia suficiente como para poder haber influido realmente en la configuracioón de la sanidad local: derogada el mismo año de 1823, fue restablecida el 15 de octubre de 1836, permaneciendo vigente hasta el 8 de enero de 1845; nuevamente puesta en vigor el 10 de agosto de 1854, hasta ser definitivamente derogada el 16 de enero de 1856.

(22) Se trata, dice el mismo S. MUÑOz MACHADO de una declaración «en cierto modo extemporánea en relación con las ideologias reinantes». Op. cit., pp. 96 y 97

(23) El mismo condicionamiento a tal extensión de la sanidad -contenido en la norma- «si los fondos públicos lo pudieran sufrir" y la financiación de tal servicio hacian previsible la inoperatividad que habría de tener tal sistema. Vid. S. MUÑOZ MACHADO: Op. cit., p. 97 y, en especial, nota 117.

(24) No obstante, se producen en esta época modificaciones destacables. Se aprueba la primera Ley de Beneficencia de 23 de enero de 1822, cuyo comentario eludimos conforme al criterio delimitador de la sanidad del que partimos. Presente relevancia en nuestro tema la creación del Ministerio de Fomento (Real Decreto de 5 de noviembre de 1832, mandando establecer la Subsecretaría de Estado y del Despacho de Fomento General del Reinol, con competencias en "el ramo de sanidad, con sus lazaretos, aguas y baños minerales», según precisaba el Real Decreto de 9 de noviembre de 1832. Igualmente, pasaron a tener competencias, y muy destacadas, los subdelegados de Fomento (Real Decreto de 23 de octubre de 1833). Pero estas normas, que produjeron efectos muy destacados en materia de sanidad, fundamentalmente centralización, no alteraron en absoluto el marco diseñado de una sanidad preventiva.

(25) Basta para comprobarlo un somero análisis de su contenido: capítulo I, "Del Gobierno Superior de la Sanidad»; capítulo II, "Del Consejo de Sanidad», en el que, aparte de su composición, sólo se contiene la posibilidad de inspecciones en casos de inminente epidemia; capitulo III, "De los empleados"; capitulo IV, "De las Direcciones especiales de la sanidad maritima»; capítulo V. "De las patentes", referente a las posibles enfermedades contagiosas declaradas en los buques; capítulo VI, "Visitas de naves», encaminadas igualmente a prevenir el contagio de las posibles enfermedades declaradas; capítulo VII, "De los lazaretos"; capítulo 
facultativos municipales de asistencia a toda la población; por el contrario, su artículo 64 establece que «Las Juntas Provinciales de Sanidad invitarán a los Ayuntamientos a que establezcan la hospitalidad domiciliaria, y a que creen con el concurso y consentimiento de los vecinos plazas de médicos, cirujanos y farmacéuticos titulares encargados de la asistencia de familias pobres, teniendo también los facultativos titulares el deber de auxiliar. con sus consejos científicos a los Municipios en cuanto diga relación con la policia sanitaria». Puede, consiguientemente, afimarse que la atención a la salud individual queda al margen de la Administración sanitaria exclusivamente ocupada por la salud pública (26).

Igual puede decirse de la Instrucción General de Sanidad aprobada "con carácter definitivo» (27) por Real Decreto de 12 de enero de 1904. Se trata de una norma que se presentaba como complementaria de la Ley de 1855 (28) y de carácter reglamentario (29) y, si bien es cierto que introdujo novedades muy destacables en materia de organización, no modificó el marco preventivo de la Sanidad pública diseñado con anterioridad. La aparición de los inspectores provinciales y municipales, como

VIII, "De las cuarentenas»; capítulo IX, "De los espurgos»; capítulo X, "De los derechos sanitarios marítimos", éste y los anteriores sobre medidas a adoptar ante buques en que se hubieran declarado enfermedades o no reuniesen buenas condiciones higiénicas. Con respecto al servicio sanitario interior, capítulo XI, "Juntas de sanidad y sus clases», exclusivamente sobre su composición y funcionamiento; capitulo XII, "Del sistema cuarentenario interior», medida posible ante casos de epidemia, capitulo XIII. "De los subdelegados de sanidad» en el que, aparte de su nombramiento, se regulan obligaciones municipales de asistencia encuadrables en el marco de la beneficencia; capítulo XIV, "Sobre expedición de medicamentos»; capítulo XV, "De los inspectores de géneros medicinales»; capítulo XVI, «De los facultativos forenses»; capítulo XVII, "De los baños de aguas minerales», en el que sólo se regula su inspección; capítulo

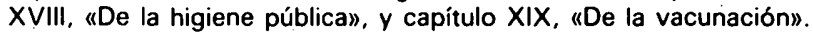

Es cierto que, como dice MARTín GONZÁLEZ esta ley, por una concepción burda de la sanidad, integra cuanto exija intervención facultativa, incluyendo la regulación de los médicos forenses o de las actividades de beneficencia, llegando, en suma, a una concepción amplísima, op. cit., II, pp. 548 y 549. Pero, en cualquier caso, queda patente la inexistencia de actividades asistenciales a toda la población.

(26) Así, acertadamente, resume R. MARTÍN MATEO la sanidad decimonónica: "A lo largo de la pasada centuria la Administración sanitaria va a estar orientada, además de a la enseñanza $e$ investigación, a la medicina preventiva y a la asistencia a grupos de población sin medios. económicos», Ordenación pública..., op. cit., p. 372.

Pese a todos, quizás el mayor defecto de la Ley de 1855 es haber estado vigente demasiado tiempo. Téngase en cuenta que, como recuerda H. C. BANDO CASADO: «Evolución histórica de la protección de la salud en España: desde 1812 hasta la Ley General de Sanidad (1986)"), Estudios sobre Consumo, núm. 8, septiembre 1986, p. 54, esta ley unos ponía a la cabeza de los textos legales europeos; solamente la Ley de Salud inglesa se había aprobado siete años antes».

(27) La Instrucción provisional se aprobó por Real Decreto de 14 de julio de 1903, șiendo sometida a información de los distintos órganos y entidades sanitarios, introduciéndose ciertas modificaciones en la Instrucción de 1904.

(28) La Ley de 1855 habia sido modificada anteriormente, aunque en aspectos no sustanciales, por Ley de 24 de mayo de 1866 y Ley de 29 de junio de 1899 .

(29) No obstante, téngase en cuenta que «se aprobó provisionalmente como decreto lo que inicialmente estabà proyectado que fuera una ley", S. MUÑOZ MACHADO Op. cit., p. 127. 
órganos básicos de la Administración périférica en la materia, recalca tal carácter y su configuración marcadamente preventiva. Más notoriamente, aún, se presenta esta tendencia en la Administración central en la que se sustituye la Dirección. General de Sanidad, configurada en la Ley de 1855 como órgano directivo en la materia, por dos Inspecciones Generales de Sanidad -Interior y Exterior- denominación que, de por sí, es suficientemente expresiva de la reducida función de estos órganos y de toda la organización pública sanitaria de la que ellos eran la cúspide (30). En la esfera local, la actividad en materia de salud se limita igualmente a los aspectos tradicionales de higiene pública y beneficiencia (31). Sí hay, por el contrario, en esta Instrucción una cierta ampliación, en la que se profundizó posteriormente, de la sanidad preventiva a los temas de las condiciones sanitarias e higiénicas del medio urbano (32). Esta tendencia que tomó cuerpo en la reforma local de Calvo Sotelo, como veremos, no afecta para nada el carácter preventivo. Tan sólo han surgido nuevos problemas, derivados de la industrialización y del crecimiento urbano, para el mantenimiento de las condiciones sociales de salud, por lo que se hacen necesarias nuevas soluciones, pero siempre dentro de los objetivos de la sanidad preventiva.

Baste este breve excurso histórico-deliberadamente detenido en la Instrucción de 1904- para comprobar que, con algunas excepciones y las matizaciones necesarias, la Administración liberal asumió tan sólo el campo de la sanidad preventiva.

(30) Las dos referidas Inspecciones se refundieron en la Inspección General del Reino por Real Decreto de 31 de mayo de 1916. órgano que se suprimió por Real Decreto de 28 de febrero de 1922, que restableció la Dirección General de Sanidad, igualmente con funciones únicamente preventivas. Cfr. M. MARTÍN GONZÁLEZ: "Dirección General de Sanidad: organización», Boletín de Documentación del Ministerio de Gobernación núm. 52, mayo-julio 1969, p. 20.

(31) El capítulo IX, bajo el título «Higiene municipal», enumera estas funciones. Su artículo 109 establece los asuntos que "pertenecen a la higiene municipal» y, si bien responde a una concepción amplia parcial (como la califica MARTín GONZÁLEZ: Sanidad pública..., op. cit., 561) por incluir servicios cuya finalidad primordial es distinta de la tutela de la salud pública -como el abastecimiento de agua o limpieza, trazado y anchura de las calles-o la asistencia a enfermos pobres, respeta plenamente la idea de una sanidad exclusivamente preventiva. Incluso la asistencia a embarazadas, que en otros momentos se generalizó, aparece aquí limitada a «embarazadas y paridas pobres» (art. 109, apartado o). Así, pues, aun afirmando que "la Administración Pública amplió su ámbito de acción en materia de sanidad con la aprobación de la. Instrucción de 1904), como hace MUÑOZ MACHADO (op. cit., p. 143), es forzoso reconocer, con el mismo autor, que se siguió dentro del campo preventivo (op. cit., p. 122).

(32) BASSOLS encuentra el punto de partida de estas preocupaciones sanitarias en la Instrucción de 1904, que dice «implica un total replanteamiento de los servicios sanitarios existentes, iniciándose una preocupación por las condiciones sanitarias e higiénicas del medio ambiental de las poblaciones...". M. BASSOLS COMA: Génesis y evolución del Derecho urbanístico español, Madrid, 1973, p. 459. Estos nuevos planteamientos encontraron su primera concreción práctica en la Real Orden de 12 de octubre de 1910, que aprobaba las "bases para la redacción de los reglamentos de higiene», y, sobre todo, en la legislación local de Calvo Sotelo, como veremos. 
Todo ello es congruente con los principios, doctrinalmente proclamados, sobre la Administración sanitaria, fiel concreción, a su vez, de los mismos postulados liberales sobre el papel de la Administración en su conjunto: si ésta, construida sobre la idea de asegurar la libertad individual, es esencialmente abstencionista y reducida básicamente a la conservación del orden público, la sanidad se limitará igualmente a los aspectos relacionados con la salud que tal concepto, con mayor o menor exactitud, puede incluir. Ello, por cierto, da origen a uno de los títulos de intervención de mayor potencial expansivo de la Administración liberal y a un sector sanitario de relativa envergadura dentro del comparativamente modesto campo de intervención pública; pero, incluso así, es mucho lo que queda fuera. Como otros muchos aspectos, la salud es considerada un bien individual $y$, como tal, sólo a cada uno interesa su consecución y mantenimiento. A la Administración, únicamente le incumben los temas sanitarios que afectan a la comunidad $y$ en tanto que las fuerzas individuales son insuficientes. Es interesante constatar cómo estos argumentos se repiten en nuestra doctrina clásica.

Así, para Posada, «sin duda la acción inmediata del cuidado de la salud es una función individual», si bien ello no impide la actuación pública aunque sólo justificada en atención a alguna de estas causas: " $1 .^{\circ}$ al carácter colectivo de los males que perturban aquélla (la salud); $2 .^{\circ}$ a la índole expansiva de dichos males; $3 .^{\circ}$ a la necesidad de una atención colectiva común para poder obrar con eficacia en el ejercicio de la función sanitaria» (33).

En parecidos términos, Colmeiro señala que umientras bastan los esfuerzos individuales para neutralizar las causas perturbadoras de nuestro organismo, la Administración abandona el cuidado de la salubridad al interés particular y la higiene es privada, más cuando los principios de la destrución resisten a la eficacia de estos medios ordinarios de combatirlas, entonces interviene la autoridad para proteger la salud de los administrados y la higiene es pública (34).

Más expresivo resulta Santamaría de Paredes para quien "como la salud se refiere a la vida del individuo, obra del individuo debe ser su conservación...; las leyes higiénicas, lo mismo que las morales y las económicas, tienen su sanción propia, según el uso que haga el individuo de esta libertad. Sin embargo, la higiene puede ser objeto de la Administración, considerada en su aspecto social..." (35).

(33) Tratado de Derecho Administrativo, Madrid, 1847, III, p. 277.

(34) M. COLMEIRO: Derecho Administrativo español, Madrid, 1865, p. 306. En palabras de MARTín GONZÁLEZ se debe a COLMEIRO «la más completa exposición de la acepción estricta dominante durante el siglo XVI) de la sanidad. Sanidad pública..., op. cit., p. 605.

(35) Curso de Derecho Administrativo, Madrid, 1888, p. 372. 
Con independencia de otras citas que podrían corroborar estas justificaciones de una sanidad limitada a la prevención y casi exclusivamente policial, sí tiene interés subrayar cómo, en gran parte, siguen latentes en doctrina más reciente, e incluso actual. Es reveladora a este respecto la afirmación de Guaita: «En principio, la sanidad es una cuestión personal (sanidad individual, salud), pero la decidida presencia de la Administración en esta materia se justifica plenamente por dos razones: primera, la existencia de ciertas enfermedades transmisibles o peligrosas; segunda, que la salud de las personas depende en gran medida del estado sanitario del país...» (36).

\section{LA SALUD PUBLICA}

En este contexto, cobra sentido y se perfila el concepto de salud pública. Es ésta la que constituye el «objeto de protección de la acción estatal» (37), al menos, la tradicionalmente cumplida por la Administración; es su tutela, el fin de lo que, convencionalmente, hemos denominado sanidad preventiva. Se identifica con lo que, hasta ahora y un tanto inexpresivamente, hemos llamado salud de colectividad (38).

Hay, sin embargo, inmediatamente que aclarar que la expresión salud pública es utilizada en muchas ocasiones en un sentido distinto. Por lo pronto, no es inusual su utilización como sinónimo de sanidad pública, confundiendo la acción estatal con el bien protegido por ésta (39). Tal identificación es reveladora de la tradicional reducción de la sanidad a la tutela de la salud pública, pero, incluso cuando tal reducción se dé efectivamente, la identificación es inexacta.

En otros casos, habituados a considerar la salud pública como el único bien protegido por la sanidad pública, se da un concepto

(36) A. GualtA: Derecho Administrativo Especial, Zaragoza, 1962, t. II, p. 155. En parecidos términos a los de los autores citados, LESSONA ha escrito que la curación del individuo atacado de enfermedad no peligrosa para los demás es algo de lo que el Estado puede desentenderse, en cuanto, de un lado, es un asunto estrictamente individual, y de otro, no cabe esperar que sean muchos los insensatos que descuiden su propia salud, en La Tutela della salute púbblica e l'agricoltura en Scritti minori, Milán 1958, pp. 59 a 61, passim.

(37) M. MARTIN GONZÁLEZ señala que "conviene distinguir entre la expresión salud pública y la tutela de la misma por el Estado (que es a lo que nos referimos cuando empleamos la expresión Sanidad Pública); entre el objeto de protección de la acción estatal y la acción misma. No obstante, este autor señala que con frecuencia se confunden las dos expresiones. Vid. Sanidad..., op. cit., pp. 421 a 425 .

(38) "Salud pública no es sino la salud de la comunidad...». M. MARTín GONZÁlez: Sanidad Pública..., op. cit., p. 423

(39) Es éste el sentido que, puede desprenderse, le da R. MARTín MATEO: "Ordenación Pública del sector salud» al definir a la salud pública, citando las definiciones de sanidad de otros autores, "como la ciencia y el arte de impedir las enfermedades, prolongar la vida y fomentar la salud mediante el esfuerzo organizado de la comunidad o como la acción estatal encaminada a...川, en RAP, núm. 84, septiembre-diciembre 1977, p. 372. 
de aquélla muy amplio en función de la progresiva extensión de ésta. Como veremos, hoy y en distintos Derechos, la Administración sanitaria desborda el marco de lo preventivo para entrar, tímida o rotundamente, en lo asistencial. Ante ello, a veces, se da un concepto amplio de salud pública, de forma que puede mantenerse que la sanidad pública protege exclusivamente la salud pública. Ello no está falto de justificación en tanto que, en ocasiones y con parte de razón, se fundamenta la ampliación de la sanidad en la existencia de un interés público, y no sólo individual, en la salud de cada uno, de forma que ésta afecta a la sociedad en su conjunto. A ello nos referiremos posteriormente. Bástenos señalar aquí que tal acepción amplia de salud pública, que en su postura más extrema pudiera llegar a considerarse el fin de la sanidad asistencial (40), no es, rigurosamente hablando, exacta; es contraria a su significado histórico; $y$, sobre todo, hace al concepto de salud pública inútil e inexpresivo.

Así, pues, sin excluir que en ocasiones, incluso en las leyes, se les atribuya otro significado, nos interesa el sentido originario de "salud pública» propio de la sanidad liberal, esto es, el conjunto de condiciones sociales que hacen posible la salud individual $o$, dicho de otra forma, el estado general que no perjudica la salud de cada individuo o, finalmente, el conjunto de condiciones de salubridad de un ambiente (41). En suma, hablamos de la salud pública como bien supraindividual y, desde luego, distinto de la salud individual.

Lo afirmado requiere dos tipos de precisiones. La primera referente a la conexión entre salubridad y salud pública, expresión aquélla especialmente habitual para referir uno de los elementos del orden público. Por ello nos referimos a la postura de considerar la posibilidad de inclusión de ciertos aspectos de la actuación administrativa de sanidad en la policía. Bástenos señalar ahora que pueden utilizarse estas expresiones de salubridad y salud pública como sinónimas $y$, de hecho, parecen ser utilizadas indistintamente en el Derecho español para referir un mismo concepto (42).

(40) Tal es la postura de FERNÁNDEZ PASTRANA: "La expresión salud pública tiene un significado amplio... de modo que abarcaría no sólo las medidas de salubridad.... la denominada Medicina preventiva, sino que se referiria también a la Medicina asistencial...l si bien todo ello está referido al significado de esta expresión en el artículo 42.2 de la Constitución, en lo cual no entramos. J. M. FERNÁNDEZ PASTRANA: El servicio público de sanidad: el marco constitucional, Madrid, 1984, p. 27. Sobre el significado de la expresión «Salud pública» en la Constitución. vid. infra. apartado 10.

(41) En parecidos términos E. BORRAJO DACRUZ define la salud pública como el conjunto de condiciones de salubridad de los distintos ambientes en los que el ciudadano se desenvuelve, en Comentarios a las Leyes Políticas. Constitución española de 1978, dirigidos por O. ALZAGA VILLAAMIL, tomo IV, Madrid, 1984, p. 182.

(42) Salud pública es la expresión utilizada por la Constitución (art. 43.2), Ley Orgánica de Libertad Religiosa (art. 3.1), Ley de Bases de la Sanidad Nacional (art. 2.1.4. ${ }^{\circ}$ ). o el Convenio Europeo de 1950 (art. 9.2, 10.2 y 11.2). A salubridad pública se refieren la Ley Reguladora de 
La segunda, la distinción entre salud pública y salud individual que, inmediatamente, hay que matizar, pues ello no supone, naturalmente, que la salud de cada uno de los individuos sea absolutamente intrascendente a la salud pública y a la actividad administrativa que cuida de su consecución. Por el contrario, «el estado de salud pública es aquel en que se hace posible la salud de los individuos», de forma que, mediata e indirectamente, ésta es protegida. Lo expresaba certeramente Stein al decir que la Administración sanitaria es el conjunto de actividades y disposiciones encaminadas $a$ asegurar las condiciones para el mantenimiento $y$ desarrollo de la salud individual, en cuanto tales condiciones están determinadas y dependen de las condiciones de la vida de la comunidad (43). Se trata, pues, de bienes distintos, cuya tutela se presentaba como diferenciable, tanto desde el punto de vista jurídico como desde el de las distintas profesiones sanitarias, pero bienes estrechamente ligados y conectados. Es más, la salud pública tiene valor por consistir precisamente en el conjunto de condiciones sociales que posibilitan el mantenimiento y desarrollo de la salud individual, como reiteradamente hemos dicho. Desde esta perspectiva y en este sentido, ambos bienes pueden identificarse (44).

También a la inversa existe relación: La salud individual influye en la salud pública, no porque ésta sea la suma de aquéllas, sino porque la salud individual, o más exactamente su contrario, la enfermedad, altera o puede alterar las condiciones sociales y la salud de los demás. En este nivel, salud pública se conecta a salud individual en tanto que «todos conllevamos la vida de todos» (45).

las Bases de Régimen Local (art. 25.2.h), el Reglamento de Servicios de las Corporaciones Locales (arts. 1.1. ${ }^{\circ}, 21 . d, 22 . d$ ), el Reglamento de Actividades Molestas, Insalubres, Nocivas y Peligrosas (art. 1) o la Ley de Orden Público (art. 2.g). A lo sumo, podría señalarse que la expresión salubridad tiene más marcada la referencia a las condiciones ambientales. Con respecto a la utilización de la expresión «salud pública» en la reciente legislación sanitaria española, vid. infra., apartado 10.

(43) L. V. STEIN: La sciencia della púbblica Amministrazione, Turín, 1897, pp. 621 y ss. Stein enuncia la citada definición de Administración sanitaríia en contraposición a sanidad pública que es la que procura al individuo las condiciones para combatir la enfermedad. No se comparte, como se ha visto, tal clasificación, al menos en lo que a los terminos empleados se refiere. Tan sólo nos interesa ahora la interrelación entre salud pública e individual. Con igual sentido BORRAJO distingue entre salud del individuo, en cuanto tal, y ula que interesa al individuo en cuanto miembro de un grupon. E. BORRAJO DACRUZ: El Derecho a la..., op. cit., p. 532. Es decir, también la salud del grupo o salud pública, interesa y tiene por testimonio final a cada individuo.

(44) Asi, FREEMAN HOMES señala que «la salud de la comunidad es algo más que la suma de la salud de sus integrantes" en Administración de los servicios de salud pública, trad. española, Méjico, 1966, p. 166. En contra, VAUGHAN: "La salud pública nunca alcanzará un nivel mejor al de la salud de que goce el individuo. La salud de la mayoría es sólo la suma de la salud personal», citado por J. J. HANLON: Principios de Administración Sanitaria, Méjico, 1963, p. 8.

(45) A. JONES: La medicina en la crisis de nuestro tiempo, Madrid, s. f., p. 2. 
La relación entre una y otra idea ha sido acertadamente puesta de manifiesto por Escribano Collado:

«La protección directa de lo que podría denominarse salud colectiva no sería sino una forma indirecta de protección de la salud individual» (46).

Así pues, la salud pública es distinta de la salud individual y, aunque ésta sea el objetivo final y presupuesto de aquélla, el Derecho puede contemplar exclusivamente a la primera sin atender siquiera a su relación con la segunda a la que puede negar relevancia jurídica para determinar la finalidad y adecuación de las concretas acciones administrativas.

5. EL INTENTO DE COMPATIBILIZAR LA ATENCION PUBLICA A LA SALUD INDIVIDUAL CON EL MANTENIMIENTO DEL AMBITO ESTRICTO DE LA SANIDAD LIBERAL

De acuerdo con lo hasta ahora expuesto, podría intentar configurarse la Sanidad pública como la actividad de la Administración encaminada a la tutela de la salud pública. Estaríamos así, definiendo la sanidad preventiva que constituía la única expresión de la Administración sanitaria liberal en su más pura manifestación. Al estar básicamente referida a condiciones sociales de salubridad, sólo incluiría entre sus preocupaciones, junto a diversas cuestiones ambientales, la atención a las enfermedades transmisibles. Fuera quedaría la sanidad curativa, la atención a la salud individual y la mayor parte de la asistencia sanitaria. La única excepción a ello estaría constituida por la asistencia sanitaria profiláctica que, al pretender realmente la protección de la salud pública y no propiamente la de la persona afectada por la enfermedad contagiosa (47), no altera en absoluto el sistema.

Esta configuración de la sanidad debe ser, no obstante, matizada. Dos factores la afectan radicalmente hasta desdibujarla en la práctica. Su origen y significado son, sin embargo, absolutamente diferentes, inciden en la sanidad de manera diversa y responden a momentos distintos. Nos referimos, de una parte, a la atención por la sanidad pública de riesgos y enfermedades no transmisibles $y$, de otra, a la asistencia sanitaria prestada por organizaciones públicas ajenas a la Sanidad.

(46) P. ESCRIBANO COLLADO: El derecho a la salud, Sevilla, 1976, p. 12.

(47) Cfr. E. ESCRIBANO COLLADO: El derecho a la salud, op. cit., pp. 22-26. 
a) Extensión puntual de la sanidad pública: la atención a riesgos sanitarios y enfermedades no transmisibles.

Con independencia de reconocer como válidos los postulados propios de la sanidad liberal, a que ya nos hemos referido anteriormente, los poderes públicos, al margen de construcciones y principios teóricos se enfrentaron e intentaron resolver específicos problemas sanitarios que desbordaban el concreto campo hasta ahora descrito haciendo insuficiente la definición propuesta. Para explicar la ampliación de la sanidad pública que ahora tratamos de describir, algún interés presenta la clasificación de enfermedades incluidas en la atención pública que realizan Mustard y Stebbins para los Estados Unidos, incluso partiendo de que «puesto que, durante generaciones, la filosofía social en los Estados Unidos ha sido mayormente individualista, es ciertamente natural que los problemas de salud se hayan dejado a cargo del individuo, concretándose el trabajo de salud pública a asumir, solamente la responsabilidad de aquellas medidas que el ciudadano, por sí solo, no podía instituir» (48). Aún así, incluyen entre las enfermedades objeto de atención pública, no sólo las transmisibles, sino también las siguientes:

- «Las enfermedades evitables... se encuentran extendidas de tal forma que determinan que la acción pública sea la única esperanza para efectuar un ataque con éxito...

- También todo aquel riesgo sanitario «cuando está lo suficientemente extendido para afectar a un número de personas relativamente grande».

En uno u otro grupo sitúan las enfermedades cardíacas, reumáticas, cáncer, higiene materno-infantil... (49).

Patente queda que, incluso partiendo, como es propio de la sanidad liberal, de encomendar al individuo todo aquello que no afecte a las condiciones de salubridad, en la práctica las organizaciones públicas entran decididamente en otros campos asumiendo ciertos aspectos de la asistencia no profiláctica. El ejemplo de la situación actual de los Estados Unidos expresa lo que constituyó durante el presente siglo la tendencia general en la evolución de la sanidad en Europa y, en particular, en España, aunque actualmente la intervención pública se haya extendido más allá de este campo:

Por distintas causas se incluyó en el campo de la Administración específicamente sanitaria la atención, asistencia y curación de

(48) H. S. MUSTARD y E. L. STEBBinS: Introducción a la salud pública, op. cit., p. 3.

(49) Ibídem, pp. 16-17, passim. 
determinadas enfermedades no transmisibles $y$, consecuentemente, irrelevantes para la salud pública, si bien afectaran a gran número de individuos. Es decir, enfermedades de indudable incidencia social, pero que no afectan a las condiciones sociales de salud.

El punto de arranque de esta tendencia puede situarse, en lo que a España respecta, en la etapa inmediatamente posterior a la Instrucción General de Sanidad de 1904 y, en especial, en la reforma de la sanidad local de Calvo Sotelo y legislación local inmediatamente posterior. En ella hay dos aspectos destacables: de una parte, una ampliación y perfeccionamiento de la sanidad preventiva, pero dentro de los límites y objetivos propios de ésta; de otra, una cierta asunción, aunque muy parcial, de la sanidad curativa.

Con respecto a lo primero -retomando la evolución histórica que detuvimos en la Instrucción General- interesa resaltar que en un marco preventivo se desenvuelve el Estatuto Municipal de 8 de marzo de 1924 (50), si bien perfeccionando notoriamente el sistema. Igual puede decirse de la Ley de Coordinación Sanitaria de 11 de julio de 1934, encaminada a hacer efectivo y real el cumplimiento de las obligaciones sanitarias de los entes locales y no a ampliarlas, o de la Ley Municipal de 31 de octubre de 1935 (51). Sí hay en esta legislación municipal del primer tercio de siglo, especialmente en el Estatuto, una expansión del campo de la sanidad en lo que a las condiciones de salubridad e higiene pública

(50) El Estatuto de 1924 presta destacada atención a las funciones sanitarias de los Ayuntamientos. El art. 150, apartado 10, establecía como competencia exclusiva de los Ayuntamientos, entre otras, las referentes a policía sanitaria, mortuoria, desinfecciones, extirpación de epidemias, o contagios y "cualesquiera otros servicios de salubridad e higiene...". El apartado 29 añadía el "saneamiento de habitaciones insalubres. Especial interés presentan los artículos 200 a 208 que incluyen entre las obligaciones sanitarias de los Ayuntamientos, además de las relativas a higiene, las de «enfermería de epidemiados» (art. 200), vacunación obligatoria (arts. 202 y 206), "establecimientos de una o varias estaciones de desinfección de mendigos, emigrantes $y$ transeúntes $y$ de una o más casas de baño gratuitas o económicas para clases pobres" (art. 205.b)... Se recoge igualmente la obligación de establecer Casa de Socorro (art. 209) pero como obligación de beneficencia. Igual carácter tiene la obligación de "crear un servicio municipal de profesores de partos» 0 "los servicios de asistencia médico-farmacéutica», pues, aunque aparecen incluidas entre las obligaciones sanitarias, están dirigidas exclusivamente a la "asistencia a familias pobres" (art. 207)

Todo ello, como se comprenderá y aunque suponga un perfeccionamiento de la acción administrativa en materia de salud, es encuadrable 0 .en la sanidad preventiva o en la beneficencia.

Para el desarrollo de estos preceptos se dictó el Reglamento de Sanidad Municipal de 9 de febrero de 1925 que no altera lo expuesto y del que sólo interesa destacar la pormenorizada regulación de las prestaciones sanitarias de la Beneficencia.

(51) Respecto a las funciones sanitarias establecidas en esta última Ley y su carácter preventivo son suficientemente expresivos los artículos 101, F, b) y 107 a 111 .

No podían tampoco ser mayores las innovaciones de la Ley de Coordinación Sanitaria de 1934 que use aprobó en espera de una nueva Ley Orgánica de Sanidad que articule de modo 
del medio urbano se refiere, fruto en gran medida de los problemas derivados de la industrialización y el crecimiento de las ciudades (52). A ello responden las normas sobre altura de las edificaciones $y$ anchura y orientación de las calles o sobre condiciones higiénicas de las viviendas (53), o la reglamentación de actividades insalubres (54), por sólo citar algunos ejemplos. A idénticas necesidades y funciones responde la creación de la Comisión Sanitaria Central y de las Provinciales (55). En todos estos casos se trata de cumplir los objetivos tradicionales de protección de la salud pública y no otros; lo único nuevo son los problemas y las soluciones, pero éstas siguen siendo encuadrables en la sanidad preventiva (56).

Es en el Estatuto Provincial de 20 de marzo de 1925 y en su desarrollo, donde se encuentran limitados, pero significativos, avances en la asistencia sanitaria no profiláctica. En el artículo 107 del Estatuto se establecía que corresponde a las Diputaciones el "establecimiento y sostenimiento de Instituciones de Beneficiencia, Higiene y Sanidad" (apartado F). La amplitud de la declaración y la referencia a la sanidad como algo distinto de la beneficencia e

amplio y preciso todas las actividades técnicas encomendadas al desarrollo de un plan positivo de reorganización sanitaria del país». Lo cierto es que la principal aportación de esta Ley -las Mancomunidades Sanitarias de Municipios- eran un instrumento para posibilitar el efectivo cumplimiento de las funciones sanitarias encomendadas a los Ayuntamientos, no para ampliarlas. Sobre el significado de esta Ley, vid. S. MUÑOZ MACHADO: La Sanidad..., op. cit., pp. 150 y ss.

(52) La conexión entre las preocupaciones sanitarias y el origen del Derecho Urbanístico encuentra en esta época su más clara expresión y ha sido reiteradamente puesta de manifiesto. Destacadamente, M. BASSOL COMA: Génesis y evolución del Derecho urbanístico español (1812-1956), Madrid, 1973, pp. 457 y ss. Vid. También E. ZAPATERO VILLALONGA: «Problemas sanitarios urbanos», en Documentación administrativa, núm. 114, junio, 1967, pp. 41 y ss.

(53) A este respecto es destacable la Base XI de las aprobadas por Real Decreto de 12 de octubre de 1910 para la elaboración de los Reglamentos municipales de higiene.

(54) El 17 de noviembre de 1925 se aprobó el Reglamento de «establecimientos clasificados de incómodos, insalubres o peligrosos». Las mismas preocupaciones por las condiciones urbanas de salubridad «derivan del examen de las llamadas Instrucciones técnicosanitarias para los pequeños municipios» aprobadas por Real Orden de 3 de enero de 1923 y otro tanto cabe decir del Real Decreto de 9 de febrero de 1925, que aprueba el Reglamento de Sanidad Municipal...) como explica S. MUÑOZ MACHADO: La Sanidad..., op. cit., p. 166.

(55) Tales Comisiones se crearon por Real Decreto de 11 de mayo de 1920, adscritas a la Inspección General de Sanidad. Fueron recogidas en el Estatuto Municipal y reestructuradas por Real Decreto de 14 de julio de 1924. A la Comisión Central le correspondía examinar los proyectos de ensanche, extensión, saneamiento y urbanización; redactar ordenanzas e instrucciones modelo en materia de saneamiento; elaborar estudios sobre condiciones higiénicas de las vías y viviendas, etc. Vid. M. BASSOLS COMA: Génesis..., op. cit., p. 460.

(56) Estamos, si se quiere describir asi, como hace A. SERIGo SEGARRA en una subfase del primer y más reducido estadio de la sanidad pública en la que se destaca el saneamiento ambiental. "La organización de los servicios sanitarios», en Boletín de Documentación del Ministerio de Gobernación, núm. 58, enero-marzo 1971, p. 22.

A lo sumo, podria hablarse de una superación de los medios policiales como único instrumento sanitario pero ni ello es absolutamente novedoso ni supone desbordar la sanidad preventiva pues ésta, como veremos, no puede identificarse con policía sanitaria. 
higiene parece indicar ya un cierto cambio en la perspectiva de las funciones administrativas en la materia. Pero tal declaración hay que ponerla en conexión, para comprender su verdadero alcance, con los artículos 128 a 130 del mismo Estatuto sobre obligaciones mínimas en el orden sanitario $y$, especialmente, con el Reglamento de Sanidad Provincial de 20 de octubre de 1925. De esta normativa se desprende la inseguridad con que tales cambios se producen y su muy reducida efectividad real.

Hay, sobre todo, especial atención a las enfermedades contagiosas $y$ epidémicas $y_{i}$ en general; a los temas de salud pública (57), que se canalizan a través de los establecimientos y medios de la Beneficencia (58) o de los Institutos Provinciales de Higiene que el mismo Estatuto establecía (59). En lo que a sanidad preventiva se refiere, la gran aportación del Estatuto es el reforzamiento de la asistencia, aislamiento y hospitalización de los enfermos contagiosos, con el consiguiente potenciamiento de los establecimientos sanitarios provinciales (60).

Pero hay también, aunque en reducida medida, atención a temas atinentes a las enfermedades no transmisibles, asumiendo parcialmente su asistencia sanitaria. Ejemplo muy destacado de ello es el del cáncer, estableciéndose la obligación de organizar una instala-

(57) Es muy significativa la Exposición de Motivos del Reglamento que, a lo que el Estatuto Provincial llamaba obligaciones mínimas en el orden sanitario, denominaba «obligaciones en orden al interés general de la salud públican. Con algunas referencias a aspectos orgánicos y de beneficencia, se limita a señalar que «en la lucha contra las enfermedades infecciosas... se obliga a las Diputaciones provinciales a organizar $y$ proveerse de cuantos medios de combate son actualmente recomendados por la ciencia sanitaria... Asegúrase de este modo la vida y desarrollo de estos orqanismos de defensa sanitaria capacitándoles de mavor dotación... que permitirá combatir con más seguro éxito las enfermedades evitables, impedir las epidemias y mejorar la vida y salud de los pueblos». Como principal novedad la referencia a "enfermedades evitables" y no únicamente a las epidemias.

(58) Es obligación de las Diputaciones «organizar a base de los establecimientos provinciales de beneficencia una sala de aislamiento para los que padezcan enfermedades infecciosas... hospitalización de prostitutas enfermas; un consultorio público gratuito de enfermedades venéreas..... Es un ejemplo más de la conexión entre Beneficencia y sanidad.

(59) Se refiere a ellos el artículo 128 c) del Estatuto y 13 a 36 del Reglamento de Sanidad. Su función esencialmente preventiva se constata en su cometido (vacunación, desinfección, zonas palúdicas, trabajos de profilaxis de enfermedades transmisibles, etc.; art. 128 del Estatuto, 30 del Reglamento) y su organización (tres secciones se preveerán: Epidemiología y desinfección; análisis clínicos, hịiénicos $v$ químicos, y vacunaciones. Art. 26 del Reglamento).

(60) Todo ello responde, como ha destacado L. MORELL OCAÑA al analizar los rasgos fundamentales de los Reglamentos sanitarios del período de Calvo Sotelo, a distinto orden de razones: En primer lugar, la convicción de que no era suficiente (como lo había sido hasta entonces) con esperar la aparición exacerbada de una enfermedad transmisible, pero que el aparato de la sanidad pública se pusiera en marcha. Era precisa, por el contrario, una prevención continua que incidiera en las causas mismas en que tienen su origen las enfermedades; en segundo lugar, que tampoco era suficiente acordonar los focos infecciosos o aislar a los enfermos infectados sino que resultaba igualmente necesario dotar a la comunidad de establecimientos donde pudieran hallar curación los enfermos aquejados de dolencias con grave incidencia social... ». "Notas sobre la reforma de la sanidad local de Calvo Sotelon, en el vol. col. Cincuentenario del Estatuto Municipal, Madrid, 1975, p. 537. 
ción radiográfica, radioterapéutica y de laboratorio para su diagnóstico y tratamiento (61); en la misma línea, puede citarse el establecimiento de un servicio de puericultura público, como obligación mínima de las Diputaciones (62).

Paralelamente, se crean en esta época distintas instituciones sanitarias, como la Escuela Nacional de Sanidad (Real Decreto 9XII-1924), Escuela Nacional de Puericultura (Real Decreto 16XI-1925), Instituto Técnico de Comprobación (Real Decreto 22XII-1925), Comisión Central de Lucha contra la Tracoma (Real Decreto 12-IV-1927), Instituto Nacional de Venereología (Real Decreto 29-VII-1933)... Esta proliferación de instituciones sanitarias, tanto nacionales como provinciales, y la ampliación de las funciones de las Diputaciones en la materia no permiten, desde luego, hablar de una verdadera sanidad asistencial. Pero tampoco puede hablarse con total exactitud de una sanidad exclusivamente preventiva; lo es en esencia (63), pero con las suficientes excepciones para que no pueda referirse tan sólo a la salud pública. Como señala Morell, "había que ampliar y efectivamente se amplió- el concepto de trascendencia o incidencia referida a la enfermedad, superándose el puro encuadramiento del mismo en lo infeccioso, para generalizarlo también a aquellas enfermedades que, aun sin ser transmisibles, suponían una grave carga para la comunidad» (64). Pero, desde el momento en que ello ocurra, y aunque se base en un interés supraindividual, se está actuando fuera de las condiciones sociales que posibilitan la salud individual, para entrar directamente en la atención a ésta; su incidencia social, aún admitiéndose, no repercute en la salud pública.

Esta ambigua situación de la sanidad pública se acentúa en la legislación posterior, tanto local $(65)$, como en la reguladora de

(61) Arts. $128 \mathrm{~B}$ y C del Estatuto. Tales funciones se canalizaban a través de los Establecimientos de Beneficencia y de los Institutos provinciales de higiene. Ello encontró muy tímido desarrollo en el Reglamento: «siendo actualmente elemento indispensable para el diagnóstico y tratamiento del cáncer una buena y completa instalación de "Rayos $X$ " " las Diputaciones Provinciales procurarán contar con ella» (art. 39).

(62) A ello se refería el artículo 128 del Estatuto, estableciéndose en el artículo 57 del Reglamento que "Las Diputaciones Provinciales organizarán un Instituto de Maternologia y Puericultura...n.

(63) En tales términos concluye S. MUÑOZ MACHADO que «la sanidad española sigue siendo, en esencia, estrictamente preventiva», La Sanidad..., op. cit., p. 169.

(64) L. MORELL OCAÑA: Notas sobre la reforma..., op. cit., p. 537.

(65) Especialmente significativa es la Ley dę Régimen Local, texto articulado y refundido de 24 de junio de 1955. En lo que se refiere a los Municipios las competencias que se les otorga y los servicios mínimos que se le imponen en materia sanitaria a los límites de la sanidad preventiva (ver arts. 101, apartado C, y 102). También es asi, en general, respecto de la Provincia a la que se imponen servicios de acondicionamiento de enfermos infecciosos, desinfección, antileproso... (art. 246) pero, para éstas y como es propio de este periodo, se incluyen actividades dificilmente encuadrables en el concepto restringido de tutela de la salud pública, como, por ejemplo, las de un Instituto de Maternología (art. 245). 
este sector sanitario. La misma Ley de Bases de la Sanidad Nacional de 1944 -que se mueve en el marco de un ordenamiento esencialmente preventivo- (66) es expresiva a este respecto en cuanto que incluye la lucha contra el reumatismo y las cardiopatías (base $8 .^{a}$ ) o contra el cáncer (base 13. ${ }^{\circ}$ ), así como la sanidad maternal e infantil (base $14 .^{\circ}$ ) (67).

Nada de ello, entiendo, puede explicarse afirmando que el campo de la prevención se ha ampliado (68), lo cual, en sí, es cierto; ni acudiendo a la consideración de que la salud pública incluye la prevención de las enfermedades en general y la curación de las socialmente trascendentes (69). Tales planteamientos, además de reformar los conceptos de prevención y de salud pública, quedan desmentidos en la misma Ley de Bases por la asunción pública de la curación de las enfermedades no contagiosas (70) y no sólo de su prevención. Se hace esto especialmente notorio en el campo de la sanidad local (71).

Ante tales cometidos de la sanidad pública hay, más simplemente, pero también más acertadamente, que afirmar que los perfiles de la sanidad no han sido en realidad tan nítidos como en línea de principios se presentaban; que, con independencia de éstos y de planteamientos ideológicos, la Administración ha afrontado problemas concretos, necesidades específicas, incluso coyun-

(66) Asi, P. P. MANSILLA considera que la Ley de 1944 «consolida la segregación de la sanidad colectiva y de la sanidad individual... de la segunda se responsabiliza a las Corporaciones Locales a través del esquema benéfico y a la sociedad a través del libre ejercicio profesional de los médicos..." "Ley General de Sanidad. Conceptos básicos y principios generales", en La reforma sanitaria en España a debate, Madrid, 1984, pp. 69 y 70. Asimismo H. C. BANDO CASADO en Evolución histórica..., op. cit., p. 58, afirma respecto de esta Ley de 1944 que su «idea del contenido de las responsabilidades públicas en este sector es... decimonónico: a la Administración pública le cumple atender aquellos problemas sanitarios que puedan afectar a la colectividad... le compete desarrollar una acción de prevención... La función asistencial... queda al margen".

(67) Con respecto a ello se ha señalado que su encuadramiento es difícil "en cuanto suponen, no protección de la salud pública, ni tampoco asistencia -prestarla a determinadas categorias de individuos, indigentes, trabajadores, escolares, niños, etc.- sino atenciones asistenciales prestadas a cuantos padezcan determinadas enfermedades, cuya trascendencia social, por su frecuencia, gravedad u otros factores, es evidente, aunque en sí no sean transmisibles y, por lo tanto, no sea ésta la razón determinante de la protección estatal. Algo semejante puede decirse de la base $14 .^{\circ}$ (Sanidad maternal e infantil) que responde más bien a una finalidad de política demográfica y que tiene naturaleza esencialmente asistencial». $M$. MARTIN GONZÁlEZ: Sanidad..., op. cit., p. 495, nota 378.

(68) En este sentido, por ejemplo, F. J. YUSTE GRIJALVA afirma que «la prevención de las enfermedades infecciosas ha sido, históricamente, la razón de ser de la Sanidad. Hoy el campo de la prevención se ha ensanchado y abarca no ya las enfermedades agudas no infecciosas, sino también los accidentes y las situaciones crónicas», en La Salud pública y el desarrollo, op. cit., p. 29.

(69) En esta línea, M. MARTín GONZÁlez: Sanidad..., op. cit., p. 646.

(70) La base $13^{\circ}$ señala que serán misiones de la lucha anticancerosa las siguientes: "Asistencia médica a los cancerosos, cualquiera que sea su clase...». Asimismo la base 14." incluye la "asistencia médica maternal».

(71) Bases 23. ${ }^{a}$, apartados primero y segundo, y $24 .^{a}$, en cuanto a casas de socorro 
turales y de carácter extrasanitario (72), desbordando los límites de la actuación preventiva impuestos por unos principios teóricamente incuestionados. Se da aquí, como en tantos otros campos de la Administración, una ampliación de sus fines y cometidos en función de las necesidades sociales $y$ al margen de una nueva «ideología previa de carácter político que venga a imponerlos con su triunfo» (73).

\section{b) La asistencia sanitaria de la Beneficencia y la Seguridad Social. Su conexión con la sanidad pública.}

Sería radicalmente erróneo deducir de la evolución hasta ahora expuesta que no ha existido ninguna asunción, ni atención pública a la asistencia sanitaria específicamente encaminada a proteger la salud individual. Más bien, se trata de que ésta se ha desarrollado en base a planteamientos distintos de los estrictamente sanitarios $y$ al margen de la Administración directamente encaminada a la tutela de la salud. Pero, aún así, matiza profundamente el panorama descrito una amplísima acción administrativa que, en base a diferentes títulos, prestaba asistencia sanitaria a gran parte de la población.

Se alude con lo anterior básicamente a las prestaciones sanitarias de la Beneficencia en favor de las personas indigentes, así como las de igual carácter encuadrables en el sistema de la Seguridad Social. Aún reconociendo su importancia, no parece difícil su exclusión de la sanidad conforme al criterio teleológico delimitador ya apuntado.

Respecto a la Beneficencia -con independencia de su origen en la secularización de servicios y la desamortización (74), ya de por

(72) Un ejemplo destacado de cómo razones ajenas a las sanitarias han influido en la extensión de la sanidad la constituye el Decreto de 27 de noviembre de 1962, sobre el que luego volveremos, que determinó la asunción por la Dirección General de Sanidad de los hospitales estatales de Beneficencia y, consecuentemente, su competencia en temas de sanidad asistencial, aunque se realizó únicamente con la finalidad de disminuir el gasto público.

(73) F. GaRRIDO FAlla: Tratado de Derecho Administrativo, Madrid, 1985, vol. I, pp. 105-106.

(74) No es esto una caso específico de la Beneficencia. Como ha observado J. L. VILLAR PALASI: «La secularización produce... los primeros servicios públicos (...) Lo que antaño era gran parte del destino de los diezmos eclesiásticos... pasa a ser carga del Estado...., en Derecho Administrativo, II, Madrid, 1979, p. 463. En el caso de la asistencia benéfica-sanitaria ello es especialmente patente hasta el punto de que, como recoge J. ORTIZ DíAZ: "Los establecimientos benéfico-sanitarios y asistenciales de las actuales Diputaciones Provinciales... históricamente, pertenecieron con personalidad jurídica, en parte a la Iglesia y a otras instituciones benéficas de çarácter privado. Como consecuencia de la desamortización, diversos de ellos pasaron al Estado y a nivel territorial, algunos a los Municipios, pero sobre todo a las Diputaciones con el carácter de benéficos para atender principal $y$ preferentemente a enfermos de esta clasen, en «Organización jurídico-administrativa y territorial de los establecimientos asistenciales a cargo de las Diputaciones Provinciales», en la obra colectiva Asistencia hospitalaria, Madrid, 1978, pp. 14 y 15. Vid. igualmente L.. MORELL OCAÑA: La evolución..., op. cit., pp. 144 a 146. 
sí expresivo de que sus planteamientos son ajenos a los propios de la sanidad pública-, es claro que en todo momento de su evolución ha tenido por finalidad la ayuda al indigente en todos los aspectos vitales y no a la protección de la salud, aunque tal ayuda se traduzca, entre otras cosas, en prestaciones sanitarias (75). Además, no afecta a toda a población, sino, aunque muy amplio, a un sector de ella (76). En suma, puede afirmarse, siguiendo a Escribano Collado, que uni los destinatarios ni su contenido convierten a la asistencia benéfica en una actividad del Estado destinada a la protección de la salud de los ciudadanos» (77). En cualquier caso, hay que añadir que la exclusión de la Beneficencia del campo de la sanidad no es simplemente una postura doctrinal, sino también, y fundamentalmente, el criterio adoptado positivamente para regular ambos sectores (78).

No muy distintos argumentos justifican la exclusión de la asistencia sanitaria de la Seguridad Social. Su mismo origen demuestra la neta diferenciación del sistema de sanidad pública y de las preocupaciones por atender la salud como un bien en sí mismo. Esta, o, mejor dicho, la enfermedad, es contemplada como un riesgo con consecuencias económicas, entre ellas las que suponen la misma curación. Si tal, o más genéricamente la asistencia sanitaria, es asumida por la Seguridad Social es para atender una específica necesidad material, junto con otras muchas

(75) Fiel a su origen de sustitución o complemento, pero, en cualquier caso, a su imagen, de instituciones de la Iglesia, al producirse la laicificación de funciones y la desamortización, su fin era tam amplio como es de las organizaciones religiosas. Así la Instrucción de la Dirección General de Beneficencias Públicas establecía las siguientes funciones: «El señalamiento de dotes a doncellas de determinadas condiciones para entrar en religión o tomar estado, las pensiones a huérfanos o jóvenes para seguir una carrera profesional o meramente científica, o para aprender un arte oficio, los auxilios para redención de cautivos, fundación de hospicios, hospitales, casas de maternidad y de misericordia; y las limosnas de cualquier cantidad y sea la que quiera la forma de distribución.»

(76) Véase sobre ello P. EsCribano Collado: op. cit., pp. 19 a 21 y J. ORTIZ diaz Organización jurídico-administrativa..., op. cit., pp. 32 a 34.

(77) P. ESCRIBANO COLlADO: El derecho..., op. cit., p. 18.

(78) Por ejemplo, J. ORTIZ DIAZ recoge que «en el Reglamento de 14 de mayo de. 1852 de la Ley de Beneficencia de 20 de julio de 1849, se incluye, bajo la rúbrica de beneficencia, servicios claramente hospitalarios. Prevalece por tanto en dicha titulación el criterio de las calificaciones socio-económicas de los usuarios o pacientes, sobre el material o sustancial de las prestaciones facilitadas», en "Hacia una ordenación de la sanidad pública española: el problema hospitalarion, en RAP, núm. 51, septiembre-diciembre 1966, p. 158. Si bien esto es cierto en la legișlación de beneficencia, podría afirmarse lo contrario a la vista de la legislación sanitaria en la que, como hemos visto, no es inusual la inclusión de regulación de temas de asistencia benéfica sanitaria. Con independencia de ello, la distribución funcional y, casi siempre, orgánica corrobora lo afirmado en el texto. Véase J. GUASP: "La beneficencia como objeto formal de la actividad administrativan, en Estudios en honor de Jordana de Pozas, tomo III, 2. Madrid, 1962, pp. 297 y ss.: F. GARRIDO FALLA: «La Beneficencia de las Entidades públicas y su conexión con la privada y las nuevas formas de Seguridad Social», en el volumen colectivo Problemas políticos de la vida social, Madrid 1964. 
que ya nada tienen que ver con la salud. Incluso la misma enfermedad (o los accidentes) dará lugar a prestaciones económicas no sanitarias. De esta finalidad de cobertura de riesgos deriva su inicial reducción subjetiva a los más necesitados. De hecho, los seguros sociales «comenzaron estableciéndose para los trabajadores por cuenta ajena de la industria y con salarios bajos... respecto de los que se pensó, aparte de la agudeza y proximidad de sus necesidades, que además eran los más necesitados de protección y que ésta era de más fácil organización» (79). Entre otras prestaciones se incluían las sanitarias, pero, como se comprenderá, no puede encontrarse aquí una verdadera pretensión de atender generalmente a la salud individual. En España, la idea cardinal de «difundir o incluir la previsión popular», con la que se creó el Instituto Nacional de Previsión (Ley de 27 de febrero de 1908), y la progresiva asunción de concretos riesgos en la que sólo fragmentariamente se fueron incluyendo específicas atenciones sanitarias (según derivaran de accidentes de trabajo, enfermedad profesional, accidente no laboral o enfermedad común) (80), ponen bien de manifiesto la imposibilidad de reconducir la asistencia que bajo tal cauce se presta a los esquemas de la sanidad pública.

Pese a las profundas transformaciones a que se vio sometido el primitivo sistema de Seguridad Social, también sus posteriores plasmaciones permiten una neta diferenciación. Por lo que a su ámbito subjetivo se refiere, aunque se recionozca como obligada tendencia el principio de universalidad, no se alcanza plenamente (81), a lo que hay que añadir las sustanciales diferencias que resultan de la diversidad de regímenes especiales. Por lo que respecta a su contenido, es, evidentemente, más amplio que el que se deriva de la atención a la salud. Su finalidad tampoco es propiamente proteger la salud. Se trata de cubrir determinados riesgos o necesidades, entre los que, entre otros, se encuentra la alteración de la salud, y ello mediante diferentes prestaciones en las que las sanitarias son sólo un tipo. Es patente, pues, que no nos encontramos ante un sector público encaminado a la protección de la salud, sino del individuo «para la satisfacción de sus necesidades

(79) A. AlONSO Olea: Instituciones de la Seguridad Social, Madrid 1983, p. 23.

(80) Ibidem, pp. 31 y ss. y 193 y ss.

(81) Vid. J. M. ALMANSA PASTOR: Derecho de la Seguridad Social, vol. I, Madrid, 1984. p. 82. En el mismo sentido M. RODRIGUEZ PIÑERO habla de la especialización objetiva y subjetiva de la Seguridad Social: «...un ámbito subjetivo de delimitación de personas tipificadas por una presunción de poder incurrir especialmente en las situaciones de necesidad predeterminadas. Entre nosotros, igual que en otros sistemas, estas personas no son otras sino las que no tienen otra fuente de riqueza que su propio trabajo...). en El Estado y la Seguridad Social, Madrid, 1964 , p. 51 
materiales, de tal manera que él y los suyos pueden llevar una existencia humana y al abrigo de la miseria» (82).

En conclusión, la protección de la salud no es ni en la Beneficiencia, ni en la Seguridad Social, la finalidad esencial o prioritaria, y, en cualquier caso, se trata de actividades administrativas que no afectan a la totalidad de la población, sino tan sólo a sectores determinados, por amplios que sean. Así, quizás resulte más exacto hablar de Beneficencia o Seguridad Social sanitarias que de sanidad asistencial, como propone Martín González (83).

Pero siendo lo anterior correcto en un plano formal, oculta la real conexión existente entre los tres sectores, conexión cuya visión resulta imprescindible para comprender el posterior desarrollo de la sanidad, su realidad actual y hasta los posibles sistemas -orgáni$\cos$ y funcionales - de una sanidad integral, comprensiva de todas las acciones encaminadas a la defensa de la salud humana. Incluso desde la perspectiva de la prevención, como forzosamente ha de ser la de este trabajo, resulta necesaria la consideración de estos sectores tangencialmente afectantes a la salud para referir los principios, los medios, los derechos y la organización en que se encuadra el concreto sector cuyo estudio trata de acometerse. De hecho, han sido muchos los puntos de contacto de Beneficencia y Seguridad Social con la sanidad preventiva.

Debe tenerse presente, por tanto, que, junto con el seguro privado de enfermedad, el único cauce organizado de asistencia sanitaria en el liberalismo es el de la Beneficencia. Que, por ello, en torno suyo, se estableció una organización pública afectante a la salud de más amplias pretensiones, si bien limitadas subjetivamente, que de la sanidad propiamente dicha: Que su regulación en el pasado siglo supuso la uprimera planificación de la asistencia médica curativa» (84). Y que, por último, a través suyo se insertaban en la Administración la mayoría de los profesionales sanitarios con que aquélla contaba, hecho éste especialmente relevante cuando la Beneficencia empieza a ver reducido su natural y originario campo de actuación.

(82) Es esta fórmula integrante de la definición de Seguridad Social de Goethem, Leen y Geysen, recogida por J. M. ALMANSA PASTOR, Ibidem, p. 83.

(83) M. MARTin GONZÁlez: Sanidad Pública..., op. cit. pp. 389 y ss.

(84) Así califica MORELL a las Leyes de Beneficencia de 1822 y 20 de junio de 1849 y Real Decreto de 14 de mayo de 1852 . "distribuyendo la competencia en tres sectores y 3 signando al Estado la cobertura de las necesidades permanentes o que reclamen una atención especial (establecimientos para locos, sordomudos, ciegos, impedidos y decrépitos); a la Provincia, el cuidado de las enfermedades comunes (hospitales generales, casas de maternidad) y a los Municipios, las enfermedades accidentales, mediante la asistencia domiciliaria. L. MORELL OCAÑA: "La evolución y configuración actual de la actitud administrativa sanitaria», en RAP 63 , septiembre-diciembre 1970, pp. 145-146. 
Con respecto a la Seguridad Social, parece innecesario subrayar su trascendencia en lo que a la asistencia sanitaria se refiere: a su cobertura de la alteración de la salud mediante, entre otras prestaciones, asistencia sanitaria, sólo hay que añadir su progresiva ampliación subjetiva (85), con especial relevancia con el proceso de deslaboralización a que ha estado sometida la Seguridad Social (86), para comprender cómo, con independencia de su exclusión formal de la Administración sanitaria, la gran mayoría de la población ha visto; a través de su cauce, atendida su salud; cómo el Estado detentó una organización capaz de una atención integral a la salud de todos los ciudadanos, y cómo, en definitiva, dejando aparentemente intactos los principios de la sanidad clásica, la realidad vivida no se ajustaba de ninguna forma a ellos.

Al margen de planteamientos de mayor alcance, la existencia de estos sectores no sanitarios, pero en los que se integran la mayoría de los profesionales sanitarios y se atiende a la salud de la mayoría de la población, no ha dejado de producir efectos en la Administración específicamente sanitaria. Las conexiones e interrelación entre los tres sectores se han producido desde el mismo momento de su coexistencia. Los ejemplos son numerosísimos, especialmente en este siglo y, sobre todo, tras la implantación del Seguro Obligatorio de Enfermedad. Baste recordar algunos: muy expresivo es el caso de los sanitarios locales en los que, con frecuencia, han coincidido las funciones de prevención o policía sanitaria, las de Beneficencia, las de asistencia a toda la población (87) o la asistencia médica de la Seguridad Social (88), de forma que se ha llegado a decir que, a nivel local, los servicios sanitarios están integrados (89); el Decreto de 27 de noviembre de 1967 que, con la finalidad de reducir el gasto público, establecía que los hospitales dependientes de la Dirección General de Beneficencia, que era suprimida, se

(85) A este respecto puede verse un apéndice estadístico sobre la extensión subjetiva de la protección en J. M. ALMANSA PASTOR: Derecho de la Seguridad Social, Madrid, 1984, vol. I. pp. 202 a 204.

(86) Vid. Ibidem, pp. 110 a 112.

(87) La asistencia a toda la población se preveía, según ya hemos visto, en la Instrucción de 3 de febrero de 1823, art. 12

(88) Ello se introdujo por la Orden de 25 de noviembre de 1947, a la que se modificó por la de 26 de enero de 1948: "Todo médico titular o de asistencia pública domiciliaria en servicio activo con plaza de propiedad e interinamente de todas las categorías será designado automáticamente médico del Seguro Obligatorio de Enfermedad...» El artículo 115.1 de la Ley de Seguridad Social, Texto Refundido aprobado por Decreto 2065/1974, de 30 de mayo, establece que "cuando las circunstancias geográficas, demográficas y laborales lo aconsejen" puede disponerse que los médicos, practicantes y matronas de los Servicios Sanitarios Locales tengan el derecho y el deber «de prestar la asistencia sanitaria de la Seguridad Social. Igualmente se recoge en el Decreto 3160/1966, de 23 de diciembre, del Estatuto Jurídico del Personal Médico de la Seguridad Social, art. 64.

(89) S. MUÑOZ MACHADO: La Sanidad pública..., op. cit. p. 215 
integraban en la Dirección General de Sanidad, órgano por excelencia de sanidad preventiva en nuestra Administración; o, por último, la previsión contenida en la Ley de Bases de la Seguridad Social de 28 de diciembre de 1963, base XV, estableciendo que ésta podrá desarrollar campañas de medicina preventiva, si bien previa coordinación con la sanidad nacional (90).

En todos estos ejemplos, y en otros que podrian traerse de parecido significado, se produce una asunción de actividades de sanidad preventiva por instituciones que ni siquiera han sido creadas en consideración a la salud, o una extensión de la sanidad a una asistencia sanitaria integrada en sistemas que atienden al individuo en todos los aspectos vitales. Los perfiles de la sanidad se hacen, así, difusos y el criterio teleológico, inicialmente aceptado, deviene, en cierta medida, excesivamente formal.

\section{LAS BASES DE LA NUEVA SANIDAD. EL OBJETIVO DE LA SANIDAD INTEGRAL}

Expuestos los principios que se suponen inspiraban el diseño de la sanidad pública, hemos referido ya como, progresivamente y por diversos cauces, se introducían modificaciones o complementos que, en definitiva, condujeron a que la realidad no obedecería sino formalmente al esquema que aquéllos imponían. Se trata ahora de destacar que, más recientemente, aquellos mismos postulados y el sistema de partida son abandonados.

Diversas causas han provocado un cambio profundo en los planteamientos sobre las funciones de la sanidad pública, tendente, en suma, a justificar y exigir la asunción de cuanto afecta a la salud individual, no ya sólo de la curación con independencia de la relevancia social de la enfermedad y de la situación social del afectado, sino incluso de la promoción de la salud (91).

$\mathrm{Si}$, como señalábamos, las características y fundamentos de la sanidad decimonónica eran esencialmente reflejo en esta materia de las generales de la Administración liberal abstencionista, tampoco la ampliación de su campo le es específica, sino inserta en el

(90) Tal previsión, que tiene su precedente en el artículo 2 de la Ley de 14 de diciembre de 1942, de creación del Seguro Obligatorio de Enfermedad, encontró su concreción en los artículos 28 y 29 del Decreto de 21 de abril de 1966, que aprobaba el primer texto articulado, así como en el texto articulado de 30 de mayo de 1974

(91) Así, incluso, habla A. SERGIO SEGARRA en «La organización de los servicios sanitarios». Boletín de Documentación del Ministerio de Gobernación, núm. 58, enero-marzo 1971, p. 23. de una última fase en la evolución de la sanidad, a la que denomina "promoción de la salud». caracterizada por la responsabilidad individual, el desarrollo de la educación sanitaria y la integración de servicios. 
fenómeno general de un creciente intervencionismo administrativo. Las causas, pues, de esta ampliación de la sanidad pública se escapan a su concreto campo y sólo desde un punto de vista más general, pueden ser comprendidas. No obstante, se presentan aquí peculiares perfiles que es necesario poner de manifiesto.

El primero, y quizás determinante, es el mismo progreso de la medicina, progreso evidente en los conocimientos y en los medios técnicos que, de una parte, ha provocado un encarecimiento de los servicios sanitarios y un aumento de las necesidades en la materia $y$, de otra, ha puesto de manifiesto la estrecha conexión entre sanidad preventiva y asistencial que, según hemos visto, aparecía negada implícitamente en el atendimiento de la salud por la Administración liberal, pese a la conexión conceptual que presentan.

Con respecto a lo primero, no merece mayor detención la constatación de que los nuevos descubrimientos científicos o meramente técnicos que hacen evitables enfermedades, o disminuyen su peligro o intensidad o, en suma, hacen remediable lo que sólo hace unos años no lo era, crean inmediatamente una necesidad social. En materia sanitaria ninguna innovación es esencialmente irrelevante; de todas ellas surge automáticamente la demanda social.

Pero, paralelamente a ello, aumenta la diferencia entre las necesidades sanitarias y las posibilidades del individuo de satisfacerlas aisladamente. El incremento de coste de los nuevos servicios sanitarios los hace inasequibles a la mayoría de la población (92). Expresivamente ha afirmado Martín González que «sanitariamente casi todos somos paraindigentes» (93). Hasta tal punto ello es así que, sin una decidida intervención pública, no sólo se produciría una notable desigualdad en el acceso a unos servicios vitales, sino que incluso, dado lo reducido de los usuarios potencialmente autosufi-

(92) El problema no es, desde luego, nuevo. Junto a los posibles beneficiarios de la beneficencia existía una gran parte de la población que no puede seguir tratamientos costosos, ni adquirir medicamentos, ni acudir a médicos privados. La solución liberal se limitaba a los seguros privados y el Estado reducía su función a fomentar tales fórmulas. Ello, que nunca fue suficiente, se hizo insostenible. M. S. ALONSO LIGERO señala, en el mismo sentido que el texto, que uel progreso científico que permite una lucha más eficaz contra la enfermedad» constituye, junto con el reconocimiento del derecho a la protección de la salud, el factor de transformación de la medicina liberal, en "El derecho a la protección de la salud», I Congreso Nacional de Derecho del Trabajo y de la Seguridad Social, vol. I, Madrid, 1981, p. 579.

193) Op. cit., II, p. 669. Añade cómo el problema no afecta sólo a la demanda, sino a la oferta «en cuanto no podrá disponer con la generalidad necesaria de los medios económicos precisos para montar los equipos técnicos modernos». En idéntico sentido ha hablado LESSONA de que, junto a los absolutamente indigentes, están los que hay que considerar indigentes en relación con la importancia de los medios diagnósticos y terapéuticos de que hoy la ciencia dispone, en Commentario sistematico alla Constituzione italiana, dirigido por P. CALAMANDREI V LEVI, Firenze, 1950, vol. I, p. 335. 
ciente, se imposibilitaría un mediano desarrollo de la asistencia sanitaria conforme a los avances científicos y técnicos (94). Desde otro punto de vista, este encarecimiento acentúa, si cabe, el problema de la distribución geográfica de los medios sanitarios especialmente costosos que resultaría, no de las necesidades de cada zona, sino de su desarrollo económico y de su población, de forma que se puedan rentabilizar las elevadas inversiones. No es ello un problema para el futuro, sino que ya hoy constituye la base y mayor dificultad para un óptimo aprovechamiento social de los descubrimientos y avances médicos. Así, ha podido decir Segerit que «la tecnología de la medicina ha dejado atrás a su sociología. Muchos problemas de salud han sido resueltos médicamente, pero socialmente permanecen sin tocar, frustrando así el progreso y malgastando las ganancias de la ciencia médica» (95).

En definitiva, el progreso de la Medicina ha hecho más necesaria la asunción administrativa de la sanidad asistencial pues el individuo aisladamente no puede proporcionarse para el mantenimiento de la salud, los medios que la Medicina ofrece (96).

(94) No obstante, los Estados Unidos sobre la base de seguros privados y Medicina liberal constituye un sistema sanitario al que se suele considerar técnicamente modélico. A ello se objeta que existe una fuente de financiación pública para investigación y enseñanza sanitaria $y$. además, que no garantiza una distribución justa del potencial sanitario. Así, RODNEY M. COE afirma que se da ula paradoja de que este país, uno de los más ricos del mundo y con medios para proporcionar una asistencia de alta calidad sin precedentes, tenga un gran porcentaje de población que no recibe ni siquiera asistencia mínima». Citado por S. MUÑOZ MACHADO: La sanidad..., op. cit., p. 200.

(95) H. E. SIGERITS citado por M. MARTín GONZÁlez: Sanidad pública..., op. cit., p. 671. Se puede, conforme a todo ello, afirmar que este desarrollo de las ciencias y técnicas sanitarias provoca una agravación de las desigualdades por causas sociales y geográficas, si no surge una intervención pública decididamente correctora. No extraña, así, que en las reformas de la sanidad ocupe un papel preponderante el principio de igualdad. Expresamente se consagra en la Ley italiana de 23 de diciembre de 1978, del Servicio Sanitario Nacional, que en su artículo 1 establece que éste atiende a toda la población «senza distinzione di condizioni individuali o sociali e secondo modalitá que assicurino l'aguaglianza dei cittadini nei confronti del servizion, y en su artículo 2 señala como primer objetivo del Servicio «il superamento degli squilibri territoriali nelle condizioni socio-sanitarie del paesse». La doctrina ha señalado al principio de igualdad como básico de la reforma sanitaria. Vid., II Servizio Sanitario Nazionale. Commento alla legge 23 dicembre 1978, núm. 833, vol. colectivo coordinado por F. A. ROVERSI MONACO. Milán, 1979, p. 10, y A. FERRo y R. IZzO: Diritto Sanitario e Servizio Sanitario Nazionale, Nápoles, 198̨2, p. 34 .

(96) MORELL afirma en este sentido que «la Administración se encuentra hoy con que el riesgo de la pérdida de la salud tiene, en multitud de casos, una magnitud tal que no es absorbible por las posibilidades individuales de previsión de la generalidad de los ciudadanos; que, en líneas generales, la capacidad individual no puede atender a su cobertura y que al individuo sólo le queda en muchos casos esperar que la comunidad le ayude en esta contingencia». L. MORELL OCAÑA: "Evolución y configuración actual de la actividad administrativa sanitaria», en RAP. núm. 63, septiembre-diciembre 1970, p. 150.

Todo ello puede considerarse como una expresión concreta en el campo sanitario del «estado de menesterosidad", en el sentido que le da a este término E. FORSTHOFF que hace depender al individuo del grupo social. Sociedad industrial y Administración pública, Madrid, 1967, pp. 46 y ss. 
Igualmente, el avance de la Medicina ha puesto de manifiesto, como anticipábamos, la conexión entre los aspectos preventivos y curativos. Por una parte, se afirma que sólo atendiendo a los segundos se puede conseguir con efectividad los objetivos de prevención: «Precisamente si queremos obtener un máximo rendimiento de nuestras instituciones médicas preventivas es preciso unificarlas entre sí y después ponerlas estrechamente en relación a la Medicina asistencial» señaló ya Pérez González (97). Por otra, se llega incluso a considerar a la Medicina preventiva como un aspecto necesario de la asistencial. En definitiva, «la medicina asistencial y la medicina preventiva son ramas que se completan y que contribuyen al mismo fin que es lograr el grado máximo de salud de los individuos») (98). La línea divisoria entre estos dos niveles de la sanidad tiende a hacerse borrosa en la misma Medicina, perdiendo consiguientemente justificación en el terreno jurídico.

Los anteriores aspectos técnicos se unen a otras causas sociales y económicas. Con respecto a lo primero, no es necesario resaltar que el valor de la salud es considerado socialmente prioritario y destacadamente respetado, siendo la sensibilidad social en estos temas superior a la de otras muchas cuestiones sociales.

Por otra parte, los aspectos económicos han hecho aparecer como relevante la salud individual. Esta, o más exactamente su falta, sólo se consideraba socialmente trascendente cuando ponía en peligro la salud de los demás; esto es, en el caso de las enfermedades contagiosas y epidémicas, y sólo en tales supuestos la sanidad pública se ocupaba de la asistencia. Con exactitud se la califica de asistencia profiláctica (99). Ahora, por el contrario, se resalta el valor social de la salud pero desde el punto de vista económico. Desde éste, la enfermedad supone una disminución de la capacidad productiva del hombre; la salud es un bien económico; y la diferencia entre las enfermedades transmisibles y no trasmisibles pasa, consiguientemente, a un segundo plano.

La constatación del valor económico de la salud no es nueva. Pero, ahora, tal aspecto se acentúa y destaca y la posible rentabilidad de las inversiones sanitarias, si no determinante, ha contribuido a facilitar el desarrollo de la sanidad. Así, puede leerse

(97) PÉREZ GONZÁLEZ: La sanidad española en el último decenio, citado por $M$. MARTín GONZÁlEZ: Sanidad..., p. 474.

(98) Conclusión de la segunda Ponencia oficial de la III Reunión Nacional de Sanitarios Españoles de 1951, citada por MARTín GONZÁLEZ: Sanidad pública..., op. cit., p. 658. En la misma línea y con mayor amplitud; dice R. MARTIN MATEO que uson hoy palmarias las estrechas vinculaciones entre la medicina preventiva, la curativa y la rehabilitación, la gravitación de la enseñanza e investigación sobre los campos prácticos...». en Ordenación pública del sector salud, op. cit., p. 378.

(99) . P. ESCRIBANO COLlADO: El deirecho a la salud, op. cit., p. 22. 
«... cien rublos gastados en sanidad producen doscientos veinte rublos en términos de renta nacional»; "los gastos dedicados a la defensa de la salud pública son los únicos productivos de riqueza, porque con ellos se da protección al capital humano»; o, finalmente, «toda actividad sanitaria... tiene una repercusión económica que la hace altamente rentable. Por una parte, evita el paro en la productividad de la máquina humana; por otra, aminora los gastos 'de reparación o mantenimiento de la misma) (100). Este aspecto económico, y no la solidaridad social, es para algunos el más decisivo en la ampliación de funciones de la Sanidad pública (101). Sin entrar en ello, sí resulta indudable que ha propiciado una confluencia de intereses de distinto signo y una superación de la salud como problema exclusivamente individual. Así, se habla ahora de que ningún bien como la salud presenta tan claramente unidos el interés individual y el social (102).

Todo ello, en suma, ha hecho insostenible los mismos principios de la sanidad liberal. Frente a la consideración de la salud como asunto, en principio, exclusivamente individual, se afirma el interés social en la salud de cada uno (103); frente a la creencia en la posibilidad de que cada individuo, aisladamente o asociándose libremente, es capaz de proteger su salud, se hace patente lo contrario. Se afirma que «la defensa a ultranza del, en este campo, anacrónico principio del laisser-faire lleva consigo ineludiblemente el de laisser-rendre malade y, a veces, el de laisser-mourin (104).

Se habla, así, de una sanidad integral a la que, en su formulación

(100) Las tres citas se corresponden al artículo de A. Serigo SEgARRA: "Aspectos económicos de los programas sanitarios». Boletín de Documentación del Ministerio de la Gobernación, núm. 56, julio-septiembre 1970; pp. 13 y 14. En este trabajo, por ejemplo, se valora la vida humana en Estados Unidos en algo más de 12.000.000 de pesetas y en España en 1.700 .000 pesetas. En parecidos términos, C. E. A. WINHLOW: Le côut de la maladie et le prix de la santé, p. 7: si el joven o adulto que con su trabajo produce para devolver a la sociedad lo que ésta le adelanta enferma, queda inválido o muere, "su existencia da un balance negativo". Desde otro punto de vista se resalta también la contribución de la elevación del nivel sanitario al desarrollo económico. Así F. J. YUSTE GRIJALVA en Salud pública y desarrollo, op. cit., p. 35, dice que ua modo de resumen podemos afirmar que la contribución primordial de la acción sanitaria al desarrollo está en suministrarle más o mejores hombres». Sobre estos aspectos económicos de la salud, vid. J. AVENTUR: Santé colective et science economique, Burdeos, 1953; A. MYRDAL: "Les aspects economiques de la santé», Revue Economique, noviembre 1952, pp. 785 y ss., y J. J. ARTELS: «Naturaleza económica de la salud y los servicios sanitarios: una revisión". Cuadernos de Economía, núm. 33, 1984.

(101) «Débese, ante todo, recordar que el valor económico de la salud y su función primordial en la economía general es precisamente lo que más ha legitimado la actividad estatal en el campo de la asistencia sanitaria, y por ello los países en que las consideraciones económicas están en primer plano han sido los primeros en aceptar, y no desde luego por razones humanitarias, la asunción total del servicio», M. MARTín GONZÁlEZ: Sanidad pública..., op. cit., p. 690 .

(102) Asi, vid. G. ZanOBINI: Corso de Diritto Amministrativo, vol. V, Milán, 1959, p. 151.

(103) Es muy expresivo a este respecto el artículo 32 de la Constitución italiana: "La República tutela la salud como derecho fundamental del individuo y en interés de la colectividad.»

(104) M. MARTín GONZÁlez: Sanidad..., op. cit., p. 695. 
más clásica, se define como «la organización sistemática de todos los servicios personales por miembros de las distintas profesiones sanitarias y de todos los recursos hospitalarios para lograr el más alto nivel de salud, prevenir, curar o aliviar las enfermedades $y$ reducir, cuando no impedir, la invalidez, la inseguridad económica y la dependencia que comporta la enfermedad... Expresa el concepto de un servicio unificado para el individuo en estado de salud o de enfermedad, en lugar de dos accesos separados: uno, limitado a la profilaxis de las enfermedades; otro, a su tratamiento. Significa asistencia médica integral cualquiera que sean las condiciones económicas del individuo, la familia, la comunidad y la nación» (105).

El mismo concepto de salud ha cambiado como resultado del progreso de la ciencia médica. Explica Ligneau que la salud, «durante mucho tiempo ha sido percibida negativamente como la ausencia de enfermedad. Era el corolario de una actividad médica limitada construida a partir de la patología»; y que esta misma «visión tradicional contribuyó hasta el fin del siglo XIX a acantonar a los poderes públicos en las intervenciones puntuales para impedir las grandes epidemias y luchar contra los tóxicos» (106). Hoy, por el contrario, se ha hecho general una concepción positiva de salud. Baste citar aquí la reiterada definición de la Organización Mundial de la Salud que la considera como uun estado completo de bienestar, físico, mental y social» (107), para poner de manifiesto las nuevas exigencias que ello supone para la acción administrativa dirigida a su atendimiento. Por lo pronto, ya no sólo es posible hablar de

(105) Es esta la definición que formularon GOLDMAN y LEAVELL en 1951 y que recogen la mayoría de los autores españoles; así, S. MUÑOZ MACHADO: La sanidad..., op. cit., pp. 204-205; L. MORELL OCAÑA: La evolución y configuración..., op. cit., p.159; M. MARTín GONZÁLEZ: Sanidad pública..., op. cit., pp. 676-677. Véase también sobre la idea y necesidad de la sanidad integral o integrada, J. ORTIZ DIAZ: «Hacia una reordenación de la sanidad pública española: el problema hospitalario", en RAP núm. 51, septiembre-diciembre 1966, p. 156; J. E. MARTíNEZ JIMÉNEZ: "Organización y reorganización de la distribución de competencias en materia de sanidad pública», en Revista de Estudios de la Vida Local núm. 176, octubre-diciembre 1972. p. 720, y J. NADAL: Planificación y gestión sanitaria, Madrid, 1985, p. 11.

(106) P. LIGNEAN: "Quelle santé? Quelle prévention?», en el vol. col. La prévention sanitarie en France, bajo la dirección de P. LIGNEAN, París, 1983, p. 2.

(107) Así, en el preámbulo del Acta constitutiva de dicho Organismo en 1948, se proclama: "La salud consiste en un estado de perfecto bienestar físico, psíquico y social, y no solamente en la ausencia de enfermedades.) Sobre este concepto de salud, vid. A. SEPELLI: "Medicina preventiva; malatie», en Dizionario di Diritto Sanitario, dirigido por G. DE CESARE y M. S. GIANNINI, Varese, 1984, pp. 338 y ss., y C. NICOLÁS ORTIZ: El derecho a la salud, Madrid, 1983, pp. 31 y 32 . 
prevenir la enfermedad y curar al enfermo sino también de mejorar e incrementar la salud (108).

\section{LA CONFIGURACION DE LA SANIDAD Y LA. PROTECCION DE LA SALUD EN LA CONSTITUCION. EL DERECHO A LA SALUD}

También la idea de la sanidad integral, como superadora de la limitada sanidad preventiva, y la misma evolución del concepto de salud ha propiciado en la Administración española transformaciones profundas. Con precedentes muy destacados en ésta misma tendencia, puede considerarse, no obstante, la consagración constituconal del derecho a la protección de la salud en el artículo 43 el punto de partida de un nuevo período que encuentra en la reciente Ley 14/1986, de 25 de abril, General de Sanidad y, en menor medida, en la Ley Orgánica 3/1986, de 14 de abril, de Medidas Especiales en materia de Salud Pública, sus instrumentos y expresión pormenorizada.

No nos interesa ahora analizar todas las consecuencias del precepto constitucional, ni la profunda reforma sanitaria plasmada en las referidas Leyes. Tan sólo nos ocuparemos de destacar los contornos y el mismo concepto de Sanidad que ello incorpora.

Desde este punto de vista, el reconocimiento del derecho a la protección de la salud, que por distintos cauces se ha generalizado en los distintos ordenamientos (109) supone, se ha dicho, "la unificación de la actividad del Estado en materia de Sanidad, es decir, su canalización a través de unos principios y un régimen jurídico unitario» (110), así como la desaparición de la asistencia por el sistema de clientelas que supone la pluralidad de organizaciones públicas como la Beneficencia y la Seguridad Social. Por el contrario, la función sanitaria del Estado comprende las necesarias para el mantenimiento de la salud de los individuos $y$, aún más, las propias de la sanidad integral que incluyen, como hemos apuntado, la promoción de la salud, la educación sanitaria o hasta la reinser-

(108). Muy interesante son al respecto estas afirmaciones de F. J. YUSTE GRIJALVA: "...La salud es algo positivo, diferente a la "no enfermedad" y que se inscribe en una curva cuyo limite está en el infinito. La salud es algo que puede perderse, ante la posibilidad de lo cual cabe un esfuerzo preventivo, y ante la realidad de su pérdida un esfuerzo curativo; pero la salud es a la vez un bien que puede mejorarse, incrementarse $y$, por tanto, son posibles esfuerzos mejorativos». Salud pública y desarrollo, op. cit., p. 26.

(109) Se recoge el texto de los preceptos de distintas Constituciones y textos internacionales que consagran el derecho a la salud, en Comentarios a las Leyes Políticas. Constitución Española de 1978, dirigidos por O. ALZAGA VILLAAMIL, T. IV, Madrid 1981, pp. 149 y 151. La OMS, en la Declaración de Alma-Ata de 12 de septiembre de 1978, afirma que la salud es un "derecho humano fundamental».

(110) P. ESCRIBANO COLLADO: El derecho..., op. cit., p. 57 
ción social del paciente, todo ello sin atender a distinciones entre las diferentes situaciones socio-económicas de los ciudadanos (111).

Parece necesario, no obstante, analizar el concreto significado del artículo 43 de la Constitución para corroborar o matizar estas ideas generales. Tal precepto supone, desde luego, responsabilizar a los Poderes públicos en todo lo referente a la salud individual, superando definitivamente, la reducción a una función exclusivamente preventiva. Además, la proclamación del derecho a la protección de la salud ha de supóner la asunción pública, no forzosamente monopolizada (112), de la atención sanitaria a cualquier persona con independencia de la situación de los individuos (113), y sin limitación, en principio, ni tan siquiera a lo que constituya propiamente curación. Sin duda la «protección de la salud" entraña un atendimiento público a la salud más amplio que el que la sanidad ha otorgado en nuestra Administración, un atendimiento tan amplio como el que inspira la idea de sanidad integral a que antes hemos hecho referencia.

Pese a todo lo anterior, no puede concluirse que el artículo 43 de la Constitución imponga necesariamente un nuevo diseño $v$ concepto de la sanidad pública. Frente a tal posibilidad, la existencia de prestaciones sanitarias por organizaciones públicas que atienden necesidades del individuo en diversidad de aspectos vitales y en los que la protección de la salud no es su fin esencial, podría conducir a canalizar a su través la efectividad del derecho a la protección a la salud. Por ello, siendo las prestaciones sanitarias de la Seguridad Social las que abarcan a la mayoría de la población, y constituyendo aquélla, por su compleja organización, capacidad y

(111) Este sistema sanitario se ha ido implantando progresivamente en distintos países y otros caminan indudablemente en la misma dirección. En España, como posteriormente veremos, es relativamente reciente la consagración de tal sistema, pero cuenta ya con interesantes ejemplos de Derecho comparado. Ya en $1972 \mathrm{~J}$. E. MARTINEZ JIMÉNEZ señalaba que «a título de ejemplo se puede decir que tal integración es ya una realidad en Inglaterra, URSS, $\checkmark$ otros paises de Europa donde la acción preventiva $、 v$ curativa es una $e$ indivisible... Organización y reorganización de la distribución de competencias en materia de sanidad pública, op. cit., pp. 720-721.

La misma OMS, en la importantísima declaración de Alma-Ata de 12 de septiembre de 1978 , diseña una sanidad que indudablemente se corresponde a la concepción integral, incluyendo $y$. conjugando los servicios de promoción, prevención, tratamiento y rehabilitación.

(112) Sobre este extremo, vid. J. M. FERNÁNDEZ PASTRANA: El servicio público de la Sanidad..., op. cit., pp. 26 a 48. Especificamente refiriéndose a la sanidad, $y$ aunque no hay aqui singularidad respecto a las nociones de la teoría general, afirma $A$. DE MICHEL que, al igual que en otros campos, "servicio público no es, de ninguna forma, sinónimo de monopolio, en Droit Medical, Paris, 1983, p. 171.

(113) Sobre esta «máxima amplitud en la configuración de su ámbito subjetivo», vid. E. B ORRAJO DACRUZ en Comentarios..., T. IV, op. cit., pp. 171 a 173. Téngase en cuenta los apartados 2 y 3 del artículo $1 .^{\circ}$ de la Ley General de. Sanidad. 
medios, la alternativa posible a la pura absorción de todos los aspectos afectantes a la salud por los órganos de la sanidad pública, la doctrina se ha centrado en la conexión y articulación entre la referencia constitucional al «régimen público de Seguridad Social» (art. 41) y al "derecho a la protección de la salud» (art. 43). La importancia de este tema a los efectos de determinar el alcance de la incidencia de la Constitución en el sistema de sanidad pública resulta evidente, pero necesario es reiterar que la Seguridad Social no monopolizaba la asistencia pública sanitaria $y$, por tanto, no agota en su totalidad la posible extensión de la Administración específicamente dirigida a la protección de la salud.

Respecto a las relaciones entre sanidad y Seguridad Social las alternativas "posibles y extremas», tal como las sistematiza Borrajo (114), son las siguientes:

1. Separación entre sanidad y Seguridad Social. La Seguridad Social se concretaría en prestaciones económicas, por no decir dinerarias; el sistema sanitario tendría a su cargo las acciones que tienen por objeto la promoción, defensa y mejora de la salud.

2. Absorción de la sanidad en la Seguridad Social, de forma que ésta englobe en su totalidad las prestaciones económicas y las distintas medidas de protección a la salud, tanto las que se hacen efectivas en forma de prestación individualizada de asistencia sanitaria, como las colectivas o de salud pública.

3. Absorción de la Seguridad Social en la sanidad, solución ésta difícilmente sostenible y desconocida en la práctica, que encomendaría a la sanidad las prestaciones económicas, al menos, las encaminadas a cubrir las necesidades y pérdida de ingresos que la enfermedad pueda suponer (115).

Junto a estas alternativas extremas, caben sistemas intermedios, a imagen del tradicional en España, "de modo que los

(114) E. BORRAJO DACRUZ: "Comentario al art. 43 de la Constitución», en Comentarios..., op. cit. T. IV, p. 159

(115) No obstante, O. ALZAGA VILLAAMILL afirma que utodo el contenido del artículo 41 es corolario del derecho a la protección de la salud...., en La Constitución Española de 1978, Madrid 1978, p. 318. Tal idea, que desde luego no aceptamos, debería traducirse orgánicamente en la absorción de la Seguridad Social por la sanidad. En esta misma dirección podría incluirse la clásica definición de sanidad integral, antes transcrita, en cuanto comprende «la inseguridad económica... que comporta la enfermedad".

En la práctica, sin embargo, no se ha encomendado en ningún Ordenamiento a la sanidad ni tan siquiera las prestaciones económicas derivadas de la enfermedad, que corresponden siempre a la Seguridad Social. Asi, por ejemplo, la Ley italiana de Instituzione del Servizio Sanitario Nazionale (Ley de 23 de diciembre de 1978, núm. 833), aún suponiendo una unificación total del sistema sanitario, encomienda las prestaciones económicas por enfermedad y maternidad al Instituto Nazionale della Previdenza Sociale (art. 74). Para la doctrina italiana se trata de "una medida correcta y coherente». L. COLOMBINI y E. VARONESI en la obra colectiva I" Servizio Sanitario Nazionale. Comento alla legge de 23 de dicembre 1978, núm. 833, coordinada por F. A. ROVERSI MÓNACO, Milán, 1979, p. 670. 
servicios colectivos sanitarios, en beneficio de la comunidad en general... se integren en la sanidad pública, mientras que los servicios individuales en beneficio de sujetos concretos y determinados investidos de un derecho regular, se mantengan dentro del cuadro de acción protectora de la Seguridad Social».

¿Por cuál de estas alternativas opta, si es que ha optado por alguna, la Constitución? Para resolver esta cuestión es necesario constatar primeramente cómo en el derecho comparado el reconocimiento separado del derecho a la salud y del derecho a la Seguridad Social no se ha entendido como consagración de la primera de las alternativas enunciadas. Si acaso, cabe hablar de una cierta tendencia hacia ella pero que no deja de mostrar como un sistema extendido y aceptado el intermedio que incluye la asistencia sanitaria como prestación de la Seguridad Social (116).

Junto a esta diversidad de fórmulas en el Derecho comparado, es de resaltar que tampoco un sistema sanitario unificado está reñido con la inclusión de las prestaciones sanitarias en la cobertura de la Seguridad Social. Basta, para armonizar las dos ideas, encomendar a ésta las condiciones y reconocimiento del derecho a las prestaciones sanitarias, negándole la organización y gestión de la compleja organización sanitaria que correspondería al servicio de salud (117). Esta variante es perfectamente congruente con los fines de la Seguridad Social: su fin no es tener servicios sanitarios propios, sino, mejor aún, que sus beneficiarios gocen de idénticos servicios que el resto de la población.

Lo anterior parece suficiente para comprender que, pese a posturas contrarias (118), el reconocimiento constitucional del derecho a la protección de la salud, incluso con su tratamiento separado de la Seguridad Social, no prejuzga una organización concreta para su atendimiento.

Ello se refuerza ante la ambigüedad de los dos artículos clave, el 41 y el 43 , menos precisos que los de otros textos constituciona-

(116) Una visión general de los distintos sistemas de los paises europeos puede verse en el estudio de la Organización Mundial de la Salud, Les services de santé en Europe, vol. 2. Copenhague 1983. Tambièn, aunque referido únicamente a los países de la Comunidad Económica Europea y centrado en la asistencia hospitalaria, vid. el vol. colectivo Les hospitaux dans le marché commun, Bruselas 1977

(117) En favor de esta especie de vafiante del sistema de separación de sanidad y Seguridad Social, se pronuncia, al menos como fórmula de transición J. M. FERNÁNDEZ PASTRANA: El servicio público de sanidad..., op. cit., p. 84. Para E. BORRAJO DACRUZ esta posibilidad es sólo una cuestión instrumental «que no destruye la configuración político-jurídica separada de uno y otro sistema», Comentarios..., op. cit., T. IV, p. 166 :

(118) Asi, por ejemplo, F. GARRIDO FALLA concluye que «...queda claro, en cualquier caso, el mandato constitucional de instrumentar el derecho a la protección a la salud fuera del régimen de la seguridad social", en Comentarios a la Constitución, dirigidos por F. GARRIDO FALLA Madrid, 1980, p. 503 
les, e incluso internacionales o supranacionales, que, sin embargo, han permitido sistemas distintos de el de una organización sanitaria unificada. Basta para justificar la anterior afirmación, y sin pretensión de agotar el tema, aludir a la referencia a la «salud pública», en el artículo 43 , y a la de «asistencia», en el 41.

1. El artículo 43, tras proclamar en el primer párrafo el derecho a la protección de la salud, establece en el segundo que a los poderes públicos corresponde tutelar la salud pública mediante medidas preventivas, prestaciones y servicios, completándose en el apartado tercero con la educación sanitaria, cuyo fomento se encomienda igualmente a los poderes públicos (119).

A la vista de la estructura y contenido de este artículo, bien pudiera entenderse, sin perjuicio de reconocer que la consagración del derecho a la protección de la salud se extiende a todos los aspectos individuales y colectivos de ésta, que el desarrollo específico de este derecho se traduce sólo en la acción preventiva (apartado 2) y de promoción o fomento (apartado 3), encontrando en la Seguridad Social cauce para otro de sus elementos: las medidas asistenciales de atención específica a la salud individual. La asistencia, aun siendo elemento del derecho de la protección de la salud, se articularía a través de la Seguridad Social.

Presupuesto para admitir esta posibilidad es entender que el artículo 43.2 de la Constitución se refiere únicamente a lo que venimos denominando sanidad preventiva. Así lo creemos efectivamente, como después se analizará (120). Baste aquí apuntar que la redacción del texto constitucional, por su ambigüedad y expresa referencia a la "salud pública», permite tal interpretación.

2. El artículo 41 de la Constitución establece:

"Los poderes públicos mantendrán un régimen público de Seguridad Social para todos los ciudadanos, que garantice la asistencia y prestaciones sociales suficientes ante situaciones de necesidad, especialmente en caso de desempleo. La asistencia y prestaciones complementarias serán libres.»

Se emplea, pues, por dos veces la palabra "asistencia», y, si bien es una fórmula ambigua, permite referirla, $o$ al menos incluir,

(119) Este párrafo se refiere también a la educación física, al deporte y a la adecuada utilización del ocio, materias que no afectan en absoluto al tema que nos ocupa. De hecho ha sido reiteradamente criticada la inclusión de tales aspectos en el artículo comentado y su asimilación a la educación sanitaria. Vid. L. CAZORLA PRIETO, en Comentarios a la Constitución, dirigidos por F. GARRIDO FALLA, op. cit., pp. 505 a 511; y E. BORRAJO DACRUZ, Comentarios..., op. cit., T. IV, p. 196.

(120) Vid. infra. epigrafe 10, a). 
a las prestaciones sanitarias (121). Si a ello añadimos la extensión universal ("para todos los ciudadanos») que da el artículo 41 , se comprenderá que es perfectamente posible instrumentar la asistencia sanitaria como contenido integrante del derecho a la protección de la salud, a través de la Seguridad Social, con independencia de las medidas de sanidad preventiva, incluida, en su caso, la asistencia profiláctica.

Con ello no queremos decir que haya de ser forzosamente así, que la Constitución opte por ese sistema concreto. Tan sólo que tal estructuración es posible dentro de la Constitución, que ésta "asume una posición neutral en la cuestión» (122).

Pero, siendo ello así, no ha de entenderse que la Constitución no suponga cambios en la organización relativa a la salud. Como ya dijimos, el artículo 41 entraña responsabilizar a la Administración en la salud individual, y no sólo en la salud pública, al reconocer, como principio rector de la política social y económica, el derecho a la protección de la salud. Dentro de los amplios márgenes organizativos establecidos en la Constitución, a los que ya nos hemos referido, hay que atender nuevos campos, porque se ha considerado constitucionalmente a la salud, la de todos y en todos sus aspectos y vertientes, un bien que ha de ser protegido.

\section{LA SANIDAD EN LA ACTUAL LEGISLACION SANITARIA}

La Ley General de Sanidad, expresa su artículo $1 .^{\circ}$. 1, «tiene por objeto la regulación general de todas las acciones que permitan hacer efectivo el derecho a la protección de la salud reconocido en el artículo 43 y concordantes de la Constitución». Tal carácter no queda desvirtuado por la simultánea aprobación de la Ley de Medidas Especiales en Materia de Salud Pública, cuya razón de ser y especificidad radica únicamente en la inclusión de su contenido en la reserva del artículo 81 de la Constitución y en la consecuente aprobación como Ley Orgánica. De hecho, el Proyecto de Ley incluía, conjuntamente, lo que posteriormente constituyó el contenido de las dos citadas leyes. Puede, pues, partirse de que el "derecho a la protección de la salud» encuentra en esta legislación la previsión completa de la acción pública dirigida a su realización.

Por lo pronto, patente queda la superación de la tendencia a acantonar en los aspectos de salud pública a la sanidad. Ni siquiera se trata de extenderla únicamente a la curación de los individuos

(121) Sobre estos extremos, cfr. E. BORRAJO DACRUZ: Comentarios... op. cit., p. 167.

1122) E. BORRAJO DACRUZ: El Derecho a la asistencia..., op. cit., p. 541. En el mismo sentido, J. M. FERnÁNDEZ PASTRANA: El servicio público..., op. cit., p. 84. 
enfermos, como corresponde al concepto clásico de salud (ausencia de enfermedades) y a la acepción tradicional de la asistencia sanitaria. Al contrario, el modelo que inspira la Ley es el de la sanidad integral. Fundamental es, en este punto, el artículo $4 .^{\circ} .1$, según el cual:

«Tanto el Estado como las Comunidades Autónomas ·y las demás Administraciones públicas competentes organizarán y desarrollarán todas las acciones sanitarias a que se refiere este título dentro de una concepción integral del sistema sanitario.»

$Y$, efectivamente, la acción sanitaria a que se refiere el título I de la Ley General de Sanidad expresa bien claramente la amplitud de las funciones encomendadas a la sanidad, que ni tan siquiera tiene como único fin la curación de las personas afectadas. En una concepción más moderna, se afirma incluso que ulos medios y actuaciones del sistema sanitario estarán orientados prioritariamente a la promoción de la salud y a la prevención de las enfermedades") (art. $3 .^{\circ}$. 1), prevención que no puede reconducirse a la idea de sanidad preventiva limitada a la tutela de la salud pública, como ya nos consta (123), sino también a la prevención de riesgos y enfermedades afectantes a la salud individual. En este mismo sentido, el artículo $6 .^{\circ} .3$, de la Ley General de Sanidad insiste en que la actuación de las Administraciones públicas sanitarias se orientará a la prevención de enfermedades "y no sólo. a la curación de las mismas».

El reflejo de ello en lo que a las concretas actuaciones que en protección de la salud han de ser realizadas por la Administración encuentra cumplido desarrollo en el artículo 18 de la Ley. Sin duda quedan incluidas las actuaciones prototípicas de la tradicional sanidad preventiva. Junto a ellas. las que pueden reconducirse a una completa asistencia sanitaria, semejante a la que venía prestándose por la Seguridad Social, aunque con pretensión de ciertas ampliaciones, o por la misma sanidad pública u otras organizaciones públicas: atención primaria integral de la salud (apartado 2), asistencia sanitaria especializada (apartado 3), prestación de productos terapéuticos (apartado 4), etc., sin que, en principio, quepa distinguir entre distintos tipos de enfermedades $y$, en particular, sin que resulte relevante a efectos de la atención pública el carácter transmisible o no y el riesgo para la colectividad. La asistencia sanitaria se presta, pues, atendiendo a la salud individual del

1123) Vid., supra., apartado 6. 
ciudadano, sin perjuicio de reconocer la concurrencia de otros intereses $y$, específicamente, el de la salud pública.

No queda, sin embargo, en lo anterior la ampliación de las acciones sanitarias de la Administración. Sin que suponga aceptar de ninguna forma que ello constituya una absoluta novedad en la actuación administrativa en este campo, si que reflejan esta nueva concepción de la sanidad que la Ley incorpora las fundamentales referencias a la uadopción sistemática de acciones para la educación sanitaria como elemento primordial para la mejora de la salud individual y comunitaria» (art. 18.1 de la Ley General de Sanidad); a ulos programas de atención a grupos de población de mayor riesgo y programas específicos de protección frente a factores de riesgo, así como los programas de prevención de las deficiencias, tanto congénitas como adquiridas» (apartado 5); a «los programas de orientación en el campo de la planificación familiar y la prestación de los servicios correspondientes» (apartado 7); a ula promoción y mejora de la salud mental» (apartado 8; nótese que la promoción y mejora de la salud mental parece desbordar el tratamiento de las enfermedades afectantes a ella), etc. Incluso la asistencia sanitaria prototípica sufre transformaciones, subrayándose finalidades distintas de la curación, para entrar también por esta vía, y no sólo la educativa o de programas administrativos específicos, en la promoción de la salud y la prevención individual. Así, en la atención primaria de la salud se incluyen expresamente, "además de las acciones curativas y rehabilitadoras, las que tiendan a la promoción de la salud y a la prevención de la enfermedad del individuo y de la comunidad" (art. 18.2 de la Ley General de Sanidad). Igualmente, en la asistencia sanitaria especializada se «incluye la asistencia domiciliaria; la hospitalización y la rehabilitación» (art. 18.3).

Todo lo anterior no es el resultado de puntuales extensiones de la asunción pública de específicos problemas de salud, sino la expresión de la responsabilidad general de los Poderes públicos en esta materia inmersa, además, en transformaciones profundas, no sólo del papel de la Administración, sino también de la misma Medicina y la función sanitaria en general. Los nuevos principios y bases de la sanidad a que antes nos referimos inspiran esta extensión generalizada que se consagra en la Ley, también y con especial énfasis, por encima de las concretas actuaciones que hayan de desarrollarse, al señalar la finalidad de éstas. Consagración acabada de ello es el artículo $6 .^{\circ}$ de la repetida Ley, que con acierto se incluye en los "principios generales», y que interesa reproducir aquí: 
"Las actuaciones de las Administraciones públicas sanitarias estarán orientadas:

1. A la promoción de la salud.

2. A promover el interés individual, familiar y social por la salud, mediante la adecuada educación sanitaria de la población.

3. A garantizar que cuantas acciones sanitarias se desarrollen estén dirigidas a la prevención de las enfermedades y no sólo a la curación de las mismas.

4. A garantizar la asistencia sanitaria en todos los casos de pérdida de la salud.

5. A promover las acciones necesarias para la rehabilitación social del paciente.»

A esta extensión sustantiva y finalista hay que añadir la subjetiva: "la asistencia sanitaria pública se extenderá a toda la población española» (art. $3 .^{\circ} .2$, LGS), e incluso a los extranjeros en los términos que se desprenden del artículo $11^{\circ}$, apartados 2 y 3 , de la repetida Ley de 25 de abril de 1986.

Todo lo anterior, se refleja en los aspectos organizativos que, para su acomodación a la nueva concepción de la sanidad pública que se implanta, sufren también modificaciones profundas que son consecuencia $y$, a su vez, expresan los caracteres del sistema sanitario que se instaura.

En este aspecto, y como expresamente señala el mismo preámbulo de la Ley, ula directriz sobre la que descansa toda la reforma... es la creación de un Sistema Nacional de Salud...n, al que se concibe como "el conjunto de los servicios de salud de las Comunidades Autónomas convenientemente coordinados». Es este sistema sobre el que se pretende hacer gravitar la protección de la salud y el que absorbe todos los medios públicos que coadyuven a tal finalidad.

Este Sistema Nacional de Salud constituye la base orgánica de la nueva idea de sanidad integral, acabando, consecuentemente, con la separación en el atendimiento a distintas cuestiones sanitarias. Integra, como expresamente proclama el artículo 45 de la Ley, "todas las funciones y prestaciones sanitarias» que la misma Ley considera «responsabilidad de los Poderes públicos para el debido cumplimiento del derecho a la protección de la salud». Ya no es posible encauzar la responsabilidad pública en lo que se refiere a la protección de la salud y el desarrollo de las correspondientes funciones en tal dirección diversificándolas en distintas organizaciones, en diferentes categorías de individuos, en diversos riesgos sanitarios... Al Sistema Nacional de Salud corresponde todo ello. 
Por eso, junto con otras, se señalan como sus características fundamentales «la organización adecuada para prestar una atención integral a la salud, comprensiva tanto de la promoción de la salud y prevención de la enfermedad como de la curación y rehabilitación» y ula prestación de una atención integral de la saluch) (art. 46, apartados $b$ y $e$ ). También en lo que se refiere al ámbito subjetivo, el Servicio Nacional de Salud realiza en todá su amplitud el derecho a la protección de la salud, estableciéndose igualmente, como característica fundamental, «la extensión de sus servicios a toda la poblaciónı (art. 46. a).

Sin perjuicio de reconocer, como hace el mismo preámbulo de la Ley General de Sanidad, que, al establecer el Sistema Nacional de Salud, «se han tenido bien presentes todas las experiencias organizativas comparadas que han adoptado el mismo modelo", parece que el sistema italiano, constituido en torno al "Servizio Sanitario Nazionale», ha influido especialmente. Como el Sistema Nacional de Salud, también el "Servizio» italiano es «individualizado como el instrumento operativo a través del cual debe ser actuado el precepto constitucional») (art. 32) que impone la tutela de la salud (124). Sobre él recae, por tanto, la totalidad de las funciones públicas relacionadas con la salud. Como dice Quaranta, el «Servizio Sanitario Nazionale» está configurado como "la entidad encargada, en su conjunto, de absorber la tarea de asegurar, en sentido lato, el bienestar físico y psíquico de la población» (125). Se configuran así como sus principios informadores el de la uglobalidad de las intervenciones» $y$, de otra parte, el de la "extensión de las prestaciones a toda la población, cayendo todas las limitaciones (antes derivadas, prevalentemente, de la existencia o no de una relación de trabajo) e introduciéndose el criterio del derecho de todo ciudadano, independientemente de la renta y de la clase social, a la tutela de la salud» (126). Como se observará, todo ello es predicable igualmente de la reforma introducida en España y, en particular, del Sistema Nacional de Salud.

Claro es, sin embargo, que esta nueva concepción de la sanidad y su traducción orgánica, el Sistema Nacional de Salud, no operan exclusivamente sobre el precedente de lo que hasta ahora consti-" tuía propiamente la, sanidad pública española. Al contrario, como hemos intentado poner de manifiesto anteriormente, la atención pública a la salud individual venía, desarrollándose ya decidida-

(124) A. QUARANTA: // sistema di assistenza sanitaria, Milán, 1985, p. 12.

(125) Ibidem, p. 10.

(126) F. ROVERSI MÓNACO y C. BOtTARI, en el volumen colectivo II Servizio Sanitario Nazionale..., op. cit., pp. 9 y 10. 
mente, aunque se hiciera al margen de organizaciones y planteamientos estrictamente sanitarios.

A la vista del desarrollo experimentado por esta asistencia sanitaria pública, fundamentalmente prestada por la Beneficencia y Seguridad Social, el panorama real no era, como pudiera deducirse de un análisis puramente formal de la legislación estrictamente sanitaria, el de una preocupación exclusiva por la salud pública. Se trataba, más bien, de una separación, cada vez más insostenible, entre la Administración preocupada por la salud pública (integrada en lo que propiamente podía denominarse sanidad pública, ya estuviera en manos de la Administración del Estado o de la local) y la que se ocupaba de la salud individual (Beneficencia estatal y, sobre todo, local y Seguridad Social); es decir, entre sanidad preventiva y curativa.

Sobre tal base, evidente resulta, que en buena medida, lo que las reformas de la Ley General de Sanidad suponen es la incorporación de un sistema único, presidido por la finalidad de defensa de la salud, de servicios, medios e instrumentos hasta ahora dispersos y formalmente dirigidos a la consecución de otros intereses. Ello, sin negar, que también se opere una ampliación de los sujetos protegidos, de las prestaciones y de las mismas finalidades.

Efectivamente, la LGS realiza, y es ello una de sus aportaciones capitales, tal integración de las distintas organizaciones públicas relativas a la salud. Es una de las consecuencias de la noción de sanidad integrada, que no sólo relativiza la distinción entre preventiva y curativa, sino que también se extiende a nuevos campos inexplorados por una y otra, según hemos visto. Pero lo cierto es que en este punto la LGS no hace sino culminar un proceso anterior en el que estaba ya presente la necesidad de aproximar y coordinar las distintas actuaciones administrativas relacionadas con la salud. La comprobación de dicha necesidad la hacía patente el mismo hecho de la progresiva extensión objetiva y subjetiva de la sanidad curativa, extensión que mostraba como absurdo seguir manteniendo un sistema basado exclusivamente en la tutela de la salud pública, mientras se desarrollaba paralelamente una compleja organización, mejor dotada, para la asistencia sanitaria, lo que conducia, en parte, a duplicar esfuerzos $y$, en parte, a infrautilizar los medios materiales y humanos con los que se contaba. Además, aún sin abordarse una reforma sanitaria general, la idea de sanidad integral estaba presente en las modificaciones parciales que venían introduciéndose, cambiando paulatinamente la radical separación de la que se partía y constituyéndose en el objetivo final a alcanzar.

Empezando, por esto último, interesante resulta la resolución sobre la Reforma Sanitaria aprobada el 6 y 7 de mayo de 1980 por 
el Pleno del Congreso de los Diputados y cuyo epígrafe número 1 , sobre los objetivos de la reforma sanitaria que la resolución propone, demuestra inequívocamente una nueva concepción de la sanidad y de los servicios específicamente sanitarios con extensión de la protección a todos los ciudadanos y en todos los aspectos de la salud, con especial atención a la promoción, educación sanitaria y autorresponsabilización personal, prevención individual..., como corresponde a una "concepción integral de la sanidad», de la que expresamente se habla, y al concepto de salud del que se parte, relacionado explícitamente con el «bienestar físico, mental y social» (127). No puede dudarse que, aunque sólo seis años después se plasmará en las nuevas Leyes sanitarias, todo ello marca un período intermedio y un proceso del que la LGS es sólo su, hasta ahora, último hito.

No podemos entrar aquí en profundidad en esta evolución, pero sí señalar, al menos, sus puntos más destacados que configuran la realidad sobre la que opera la LGS.

Hay que comenzar por señalar, que reducir esta evolución a los servicios específicos de sanidad, los de Beneficencia y los de

(127) Interesa reproducir aquí los objetivos que se atribuian a la reforma sanitaria en esta Resolución publicada en el «Boletín Oficial de las Cortes Generales, Congreso de los Diputados», Serie G, 14 de mayo de 1980, núm. 3.II:

«Mediante la Reforma Sanitaria se pretende conseguir un sistema que garantice a todos los ciudadanos españoles, cualquiera que sea su situación o condición, el derecho a la protección de la salud reconocido en el artículo 43 de la Constitución. Este objetivo final ha de conseguirse a través de:

- La elevación del nivel de salud de toda la población española incrementando su bienestar físico, mental y social y suprimiendo los desequilibrios interterritoriales y sociales actualmente existentes.

- La defensa y promoción de la calidad del medio ambiente en general y de los lugares de trabajo en especial y la salvaguarda de la salubridad y de la higiene de los alimentos.

- La responsabilización del ciudadano en su propia salud.

- La creación de una conciencia sanitaria basada en la educación en materia de salud de los ciudadanos, considerados individualmente y de la colectividad en su conjunto.

- La prevención de los procesos patológicos.

- El diagnóstico y tratamiento de las enfermedades.

- La rehabilitación de los estados de invalidez tanto somática como psíquica.

- El control de la experimentación, producción, distribución y dispensación de los medicamentos y de las informaciones científicas acerca de sus acciones terapéuticas con el fin de garantizar su calidad, seguridad, eficacia y economía.

- La formación continuada del personal sanitario y la creación de las nuevas profesiones que una concepción integral de la Sanidad vaya demandando.

- El fomento de la investigación científica sanitaria en sus diversas modalidades.

Para la consecución de estos objetivos ha de buscarse el máximo rendimiento de los recursos disponibles evitando tecnologías inútiles y empleando con criterios sociales las inversiones y los gastos en una conciencia de la responsabilidad y eficiencia tanto personal como colectiva. En consecuencia, al ser la demanda de salud de carácter continuo y creciente, en tanto que los recursos son limitados, los programas han de ajustarse a las posibilidades reales de la comunidad, y los índices de crecimiento de los servicios de salud no han de sobrepasar sus disponibilidades económicas». 
Seguridad Social es una simplificación, pues, en realidad, la insuficiencia e inadaptación de cada uno de éstos a las nuevas necesidades provocó tal situación de dispersión competencial en temas de salud que, en algunos momentos, reduciéndonos a la Administración del Estado, era difícil encontrar Ministerios que no tuvieran a su cargo algunas funciones en la materia (128). Incluso así, es suficiente, a nuestros efectos, ocuparnos únicamente de los tres referidos campos.

Respecto a los sectores de Beneficencia y sanidad pública se producen dos hechos que merecen ser destacados. El primero, la integración en la Dirección General de Sanidad de los hospitales dependientes de la Dirección General de Beneficencia en 1967 (129), integración que, pese a producirse por consideraciones económicas y no sanitarias, supone una innovación relevante en la Sanidad que pasaba, así, a atender la salud individual, aunque tan sólo de los indigentes. De esta forma, se conseguía una cierta unificación de los servicios sanitarios, con independencia del título jurídico por el que se tuviese acceso a ellos. Ello, sin embargo, no supuso una modificación sustancial en la Beneficencia de la Administración local, en la que, como nos consta, la integración con los servicios estrictamente sanitarios era superior. El segundo, la creación por Decreto-ley 13/1972, de 20 de diciembre, del Organismo Autónomo denominado Administración Institucional de la Sanidad Nacional, en el que se integraban los centros asistenciales hospitalarios de la Dirección General de Sanidad; es decir, tanto antiguos hospitales de Beneficencia, como los existentes para tratamiento de enfermedades socialmente relevantes con funciones

(128) Así lo demostraba puntualmente, enumerando hasta dieciséis Ministerios, J. E. MARTINEZ JIMÉNEZ en Organización y reorganización de la distribución de competencias en materia de Sanidad pública, op. cit., pp. 701 y ss., si bien es cierto que parte de un concepto de Sanidad excesivamente amplio. De todas formas interesa recoger algunos ejemplos de esta situación de 1972: Ministerio del Ejército, entre otros, con competencias en la asistencia sanitaria a los miembros del Ejército (Dirección General de Acción Social), Sanatorios antituberculosos (Dirección General de Servicios), formación de personal sanitario (Escuelas de Sanidad del Ejército); Ministerio de Marina: asistencia sanitaria a los miembros de la Armada; Ministerio de Educación y Ciencia: competencias en inspección y asistencia médica de escolares; rehabilitación de inválidos; Ministerio de Agricultura: Sanidad de productos de origen animal (Dirección General de Producción Agraria); Ministerio de Comercio: ordenación de productos alimenticios de origen marino, etcétera. Junto a ello, los propios del Ministerio de Gobernación (Dirección General Sanidad) y Ministerio de Trábajo (Seguridad Social).

(129) Tal «refundición» se operó por un Decreto de 27 de noviembre de 1967, dictado en virtud de un Decreto-ley de la misma fecha, de ordenación económica, que autorizaba al Gobierno a la supresión, refundición o reestructuración de organismos, para disminuir el gasto público. No obstante, según el artículo 5 del citado Decreto, lo único que pasaba a la Dirección General de Sanidad eran los hospitales; las restantes funciones de la Beneficencia, así como el Fondo de Protección Benéfico-Social, pasaban a la Dirección General de Política Interior y Asistencia Social. 
propias de sanidad preventiva (130), por lo que, en definitiva, se consolidaba la refundición a nivel central de Beneficencia y sanidad (131).

Dicho lo anterior, es forzoso reconocer que, fundamentalmente, es la Seguridad Social e! sector en el que se encuentra el desarrollo de la asistencia sanitaria y que, en torno a su conexión con el sistema de sanidad, se desenvuelve la clave de la atención integral a la salud.

La Ley de Bases de la Seguridad Social de 28 de diciembre de 1963 y su primer texto articulado, aprobado por Decreto de 21 de abril de 1966, supusieron pasos importantes en el tratamiento de la salud individual, tanto por la ampliación subjetiva y objetiva de las prestaciones sanitarias, como por la configuración específica de la asistencia sanitaria (132). Pero, al mismo tiempo, confirmaban la independencia respecto de la Administración propiamente sanitaria de este amplio sistema de atención a la salud individual y consagraban el atendimiento de ésta en base a títulos específicos, y no simplemente por la ciudadanía. No se caminó en el sentido de separar los temas de salud de la Seguridad Social, sino, justamente, en el contrario, de forma que, si de unificación de los servicios de salud hubiese que hablar, ésta vendría de la mano del crecimiento de la Seguridad Social, no de sus desgajamientos. Hasta tal punto ello es así, que la conexión entre la sanidad preventiva y curativa vino, en esta legislación, por la asunción también de aquélla por la Seguridad Social (133).

La sanidad pública quedaba, al margen de este extenso sistema de asistencia sanitaria, inmune, al parecer, a las profundas transformaciones que los tiempos demandaban y cuya respuesta se

(130) Así, el artículo 1 del Decreto-ley 13/1972, de 29 de diciembre, al enumerar los centros integrados en tal organismo incluye, entre otros, el Gran Hospital de la Beneficencia General del Estado y el Hospital Nacional de Enfermedades Infecciosas.

(131) La razón de ser de la creación de este Organismo, como se deduce de la misma exposición del Decreto-ley, es ula necesidad de establecer un régimen económico-administrativo más ágil». Verdaderamente, no supone en realidad ni siquiera una descentralización institucional o ésta es «totalmente ficticia... puesto que la gestión del organismo se hace directamente desde los servicios centralizados de la Dirección General de Sanidad», como afịrma S. MUÑOZ MACHADO: La Sanidad..., op. cit:, p. 182. Y ello, tanto según la estructura orgánica diseñada en este Decreto-ley (art. 2.2 y Disposición final $1 .^{9}$ ) como, sobre todo, tras la reforma operada por Decreto de 25 de enero de 1974.

(132) Así, E. BorRajo DACriuz dice que «la Ley de Bases... y los textos articulados... pudieron avanzar por esta via; $y$ algo hicieron, en efecto, al separar la asistencia sanitaria $y$ configurarla como una prestación específica, con entidad propia pero siempre dentro de la Seguridad Socials, en El derecho a la asistencia..., op. cit., p. 531.

(133) Nos referimos a la ya citada base XV de la Ley de 28 de diciembre 1963, arts. 28 y 29 del Texto articulado de 1966 y de 1974 (Decreto de 30 de mayo). Todos ellos permitiendo a la Seguridad Social, previa coordinación con la Sanidad Nacional, realizar campañas $y$ desarrollar programas de Medicina preventiva o colaborar en los que se extienden a toda la población del país. 
consideraba exclusiva responsabilidad de la Seguridad Social (134). Inmune quedaba también la división por clientelas, no obstante; ello con una excepción muy destacable $y$ 'de gran trascendencia en lo que a la coordinación de los distintos sectores públicos con responsabilidades en materia de salud se refiere: el principio de hospitales abiertos que, uen relación con todos los enfermos, cualquiera que sea su condición social y económica», proclamó el artículo 2 de la Ley de Hospitales de 21 de julio de 1962 (135).

Desde esta formal separación de la sanidad pública y la compleja organización sanitaria de la Seguridad Social se ha ido caminando hacia su progresiva coordinación e integración. Punto de necesaria referencia en este proceso es el período constituyente $y$, concretamente, dos hechos fundamentales.

El primero de ellos viene constituido por el abandono de la estructura tradicional española de una Dirección General de Sanidad, incluida en el Ministerio de Gobernación y con competencias únicamente en lo relativo a salud pública. Ello se operó por Real Decreto 1558/1977, de 4 de julio, de reestructuración de determinados órganos de la Administración central del Estado, que creó el Ministerio de Sanidad y Seguridad Social (art. 12), en el que se integraban la Dirección General de Sanidad, los órganos provenientes del Ministerio de Trabajo con competencias en materia de Seguridad Social, así como «las entidades estatales autónomas, servicios, instituciones, organismos... y demás entidades adscritas a los Ministerios de Trabajo y Gobernación a través de los centros directivos que se traspasan o vinculados a ellos por razón de dirección, vigilancia, tutela o protectoradon, y entre ellos, evidentemente, la Administración Institucional de la Sanidad Nacional (136), en la que, a su vez, según vimos, se habian integrado centros sanitarios de la Beneficiencia y de la sanidad. Se encontra-

(134) . Con razón, pues, sintetiza S. MUÑOz MACHADO la situación afirmando: «La Administración, que tuvo que crear hospitales para pobres y colaborar en la asistencia sanitaria de los trabajadores, sigue sin preocuparse de forma directa e inmediata por la salud de los individuos... El efecto, inmediato de la implantación de la Seguridad Social es que la Dirección General de Sanidad perderá capacidad expansiva... incluso va perdiendo capacidad y posibilidades de desarrollar las tradicionales competencias preventivas», en La Sanidad..., op. cit., pp. 193-194.

(135) S. AlVAREZ GeNDIN en Régimen Administrativo de la Sanidad, op. cit., p. 422, destaca la importancia de esta Ley que supone, según él, que ya uel régimen hospitalario es de carácter sanitario, no simplemente benéfico, como lo que hasta la Ley de Hospitales de 21 de junio de 1962\%. La afirmación no nos parece completamente exacta pero patentiza la trascendencia del paso dado por dicha Ley. Sobre su signíficado e importancia, vid., también P. J. SANZ BoIXARELL: "La Ley de Hospitales como Ley de Coordinacióni,, Documentación Administrativa núm. 105, septiembre 1966.

(136) Así lo confirma el art. 17.3 del Decreto 1918/1977, de 29 de julio, sobre estructura y funciones del Ministerio de Sanidad y Seguridad Social, que adscribe a la Subsecretaría de Salud la "Administración Institucional de la Sanidad Nacional»). 
ban, así, los tres sectores fundamentales afectantes a la salud, de tan distinto origen y finalidad (atención al indigente, al trabajador y a la salud pública), aunque, junto con ellos, aparecían órganos y servicios que ninguna relación guardaban con la atención sanitaria, sino con las otras prestaciones de la Seguridad Social (137). Aún así, e incluso reconociendo que se trataba de una estructura provisional (138) y que no venía acompañada de ninguna reforma sustantiva de la sanidad y Seguridad Social, forzoso es reconocer que esta reorganización ministerial permitió una primera unificación de competencias en la materia y una mayor coordinación de los servicios relativos a la salud, especialmente en lo relativo a la asistencia sanitaria, y ello, fundamentalmente, sobre la base de una específica Subsecretaría con competencias generales en materia de sanidad y una Dirección General de Asistencia Sanitaria a la que incumbe ésta, ya sea prestada por la Beneficiencia, la Seguridad Social o la sanidad (139). Las subsiguientes modificaciones del Ministerio de Sanidad y Seguridad Social no hicieron sino profundizar en las líneas ya marcadas (140).

(137) No ocurrió nada semejante en 1967 con lo relativo a Beneficencia de la que sólo se habían integrado en la Dirección General de Sanidad, y posteriormente en la AISN sus hospitales. como expusimos. En el caso de la Seguridad Social, por el contrario, fue la estructura completa de ésta la que se unió a la Sanidad en un único Ministerio.

(138) La misma exposición que precede al artículo del Real Decreto precisa que éste «limite su alcance a una primera fase de reestructuración administrativan, lo que resulta especialmente cierto en lo que al Ministerio que nos ocupa se refiere, ya que al mismo tiempo que éste, se creaba «una Comisión Mixta de los Ministerios de Trabajo y Sanidad y Seguridad Social que propondrá al Gobierno el definitivo reparto de atribuciones y competencias en materia de Seguridad Social...) (art. 12.2).

(139) La estructura orgánica del Ministerio de Sanidad y Seguridad Social fue desarrollada inicialmente por el Real Decreto 1918/1977, de 29 de julio, y Orden de 21 de octubre de 1977. En estas disposiciones se atribuía a una específica "Subsecretaría de Salud», que coexistía con la Subsecretaría del Departamento, la competencia general en la materia. Ello se modificó por Real Decreto 2436/1978, de 14 de octubre, por el que la Subsecretaría de Salud se convertía en Subsecretaría del Departamento. Pero, al crearse en el mismo Real Decreto la Secretaría de Estado para la Seguridad Social, la Subsecretaría del Departamento quedaba como órgano casi exclusivamente sanitario.

Con anterioridad, existía en el Ministerio de Trabajo una «Dirección General de Ordenación y Asistencia Sanitaria de la Seguridad Social». Con la reorganización que analizamos la Dirección General de Asistencia Sanitaria asumía todas las funciones del nuevo Ministerio en «planificación, coordinación y propuesta de ordenación de la asistencia sanitaria, tanto hospitalaria como extrahospitalaria» (art. 18 del Real Decreto 1918/1977, de 29 de julio). De esta forma la ya centenaria Dirección General de Sanidad, que pasaba a denominarse Dirección General de Salud Pública, perdía todas sus competencias en materia de asistencia profiláctica.

(140) Fundamentalmente se produjeron por Real Decreto 3302/1978, de 22 de diciembre; Real Decreto 933/1979, de 27 de abril; y Real Decreto 1274/1980, de 30 de junio. Supusieron: $1 .^{\circ}$ La consolidación de un órgano con competencias generales en materia de salud que se transformó en "Secretaría de Estado para la Sanidad», de acuerdo con el Real Decreto 933/1979 que, al mismo tiempo suprimía la Secretaría de Estado para la Seguridad Social (cuyas funciones pasaban a la Subsecretaría del Departamento). Secretaría a través de la cual se adscribían el INSALUD y la AINS; $2 .^{\circ}$ La configuración de una Dirección General como centro superior de planificación y coordinación de la asistencia sanitaria de todo tipo a la que se denomina Dirección 
El segundo hecho viene determinado por el Real Decreto-ley $36 / 1978$, de 16 de noviembre, sobre gestión institucional de la Seguridad Social, la Salud y el Empleo. En lo que ahora nos interesa, hay que destacar la creación del Instituto Nacional de la Salud (INSALUD), como entidad gestora de la Seguridad Social para la administración de sus servicios sanitarios (art. 1.2), y la confirmación de la. Administración Institucional de la Sanidad Nacional (AISN), como organismo autónomo del Estado «para la gestión de los servicios de prevención y asistencia que tenga encomendados» (art. 2.1). Al INSALUD no se le encomendó sólo "el desarrollo y ejecución de las funciones y actividades precisas para hacer efectivos los servicios y garantizar las prestaciones sanitarias de la Seguridad Social», sino también las funciones «relativas a medicina preventiva, promoción de la salud individual, medicina de comunidad y asistencia sanitaria, mediante conciertos con la Administración estatal, institucional, territorial y local» y ula coordinación funcional de las actividades de las instituciones públicas o privadas, mediante el establecimiento de acuerdos, conciertos, convenios o fórmulas de gestión integrada o compartida con otras entidades públicas o privadas, para el mejor cumplimiento de fines sanitarios» (art. 1 del Real Decreto 1855/1979, de 30 de julio, sobre estructuras y competencias del INSALUD). Aun sin entrar a precisar la concreta extensión de sus funciones, es obvio que desborda el marco de la asistencia sanitaria de la Seguridad Social. Pero tampoco lo relativo a ésta se le encomendó en su totalidad: al Instituto Nacional de la Seguridad Social corresponde «el reconocimiento del derecho a la asistencia sanitaria» (art. 1.C del Real Decreto 1854/1979, de 30 de julio, sobre estructura y competencias del Instituto Nacional de la Seguridad Social). EI INSALUD quedaba adscrito al Ministerio de Sanidad y Seguridad Social, a través de la Subsecretaría del Departamento, al igual que la Administración Institucional de la Sanidad Nacional (141).

Estos dos hechos han marcado la evolución posterior. De una parte, en el INSALUD se han ido integrando organismos sanitarios que aún habían permanecido al margen de este proceso (142). De

General de Planificación Sanitaria (art. 7 del Real Decreto 1274/1980), y 3. ${ }^{\circ}$ Reducción de la Dirección General de la Salud Pública (antes dénominada de. Sanidad) exclusivamente a aspectos preventivos y ni siquiera a todos ellos.

(141) Real Decreto 3302/1978, de 22 de diciembre.

(142) La unificación de los servicios relacionados con la salud, recibió un nuevo empuje con el Real Decreto 2001/1980, de 3 de octubre, que integraba en el INSALUD al Instituto Nacional de Medicina y Seguridad en el Trabajo, Escuela de Medicina del Trabajo, Clínica de Enfermedades Profesionales, Organización de los Servicios Médicos de Empresas e Instituciones Territoriales de Higiene $y$ Seguridad en el Trabajo (Disposición final primera). Además se establecía que el Director General del INSALUD «asumirá la Jefatura y dirección del Organismo Autónomo Administración Institucional de la Sanidad Nacional», coincidencia personal que, aun 
otra parte, las sucesivas reorganizaciones de los Departamentos se han dirigido a concentrar en un solo Ministerio todas las competencias en materia de salud; con exclusión de los restantes aspectos de la Seguridad Social. Primero, la creación en 1981 del Ministerio de Trabajo, Sanidad y Seguridad Social (143), y poco después, en el mismo año, la del Ministerio de Sanidad y Consumo (144), ultiman esta progresiva aproximación y coordinación de la atención

dejando intacta la personalidad jurídica de ambas organizaciones, suponía un grado máximo de coordinación. No creemos, sin embargo, que esta identidad de Jefatura pueda entenderse, como lo hace J. M. ALMANSA PASTOR como si se hubiera establecido una ututela administrativa de segundo grado» en la que "un organismo autónomo queda sometido a una identidad gestora de la seguridad social», en Derecho de la Seguridad..., op. cit., p. 240. La tutela sigue correspondiendo directamente a la Administración del Estado a través del Ministerio de Sanidad, y particularmente, de la Secretaría de Estado, como lo demuestra la competencia para el nombramiento de su director. Ningún cambio supone al respecto la coincidencia personal.

(143) Por Real Decreto 325/1981, de 6 de marzo, se suprimió el Ministerio de Trabajo y el Ministerio de Sanidad y Seguridad Social, creándose el Ministerio de Trabajo, Sanidad y Seguridad Social, cuya estructura orgánica se desarrolló por Real Decrëto 428/1981, de 13 de marzo.

La fusión, si así se la puede llamar, de este tercer sector, la Administración propiamente laboral, puede parecer contraria a la evolución hasta ahora descrita y, en cierto modo, distorsionadora de las difíciles relaciones entre sanidad y Seguridad Social. Nada une al mismo tiempo a estas tres ramas administrativas, aunque la Seguridad Social tenga aspectos comunes con las otras dos. Trabajo y sanidad sólo coinciden, por decirlo gráficamente, por mantener. relaciones intimas con la Seguridad Social, pero entre si nada tiene que ver. No obstante, esta coincidencia en un único departamento parecía estar encaminada a preparar una nueva división ministerial de los servicios y competencias entre trabajo y sanidad más racional que la hasta ese momento existente en la que toda la Seguridad Social se había desgajado de aquél e integrado en ésta. De hecho, el mismo Real Decreto de creación del nuevo Ministerio señala que se trata de una integración provisional. Es, pues, este carácter de preparación de la posterior $y$, al parecer, definitiva organización lo más relevante de la corta existencia de este Ministerio de Trabajo, Sanidad y Seguridad Social. Interesa destacar, no obstante, que en este «macroministerio" subsistió, junto a las Secretarías de Estado de Empleo y Relaciones Laborales y de Seguridad Social, la de Sanidad que no sufrió sustanciales modificaciones (ver art. 5 del Real Decreto 428/1981) conservando su carácter de órgano con competenciás yenerales en todas las materias de salud y la adscripción del INSALUD.

(144) Por Real Decreto 2823/1981, de 27 de noviembre, se crea el Ministerio de Sanidad y Consumo (art: 1) y el, hasta entonces, Ministerio de Trabajo, Sanidad y Seguridad Social pasa a denominarse Ministerio de Trabajo y Seguridad Social. Esta reestructuración, que puede parecer fruto de acontecimientos concretos (particularmente, al envenenamiento de aceite de colza) y consiguientemente tan provisional como las anteriores, supone, sin embargo, ultimar las consecuencias de la evolución de las relaciones entre sanidad y Seguridad Social hasta aquí descritas.

Aunque nominalmente esta reforma parezca dejar las cosas como estaban inicialmente $y$ hasta 1977 -esto es, separación entre Sanidad y Seguridad Social- no es así porque, tras su unión provisional, una y otra habían cambiado sustancialmente. Ahora, de la Administración sanitaria no dependen tan sólo los servicios preventivos, lo tocante a la salud pública, sino también todo lo relativo a la salud individual, incluida la asistencia correspondiente a la Seguridad Social, tal y como hemos ido viendo que se perfilaba con las Subsecretarías o Secretarias de Estado, según el momento, de Sanidad; con la Dirección General de Asistencia - Planificación Sanitaria; con la adscripción de la AINS y del INSALUD, etc.; tampoco el sistema de Seguridad Social había permanecido inmutable. La distinción dentro de las entidades gestoras del INSALUD y la extensión de las funciones de éste a la medicina preventiva habían permitido y propiciado una separación orgánica y funcional respecto de las restantes entidades gestoras de organismos autónomos.

Nada de ello desaparece. La nueva estructuración mantiene esa estrecha conexión entre la sanidad y los servicios de la asistencia sanitaria de la Seguridad Social que, en definitiva, se 
a la salud pública y de la asistencia sanitariá en lo que se refiere a la organización de la Administración central del Estado.

Desde luego, la existencia de un Ministerio de Sanidad supuso una mayor conexión y mejor coordinación de los sistemas existentes, pero dejando a salvo su entidad y peculiaridades propias de cada uno y la insuficiencia del conjunto.

En esta misma línea, la LGS opera con mayor profundidad e intensidad $y$, además, lo hace ya sobre todas las organizaciones públicas relativas a la salud y no sólo a las de la Administración del Estado. Esto constituye una novedad, especialmente destacable no sólo por cuanto incorpora a las Comunidades Autónomas, a las que se habían transferido gran parte de las funciones y servicios en la materia, sino también a las Administraciones locales, de las que tradicionalmente dependía la asistencia benéfico-sanitaria. No entraremos nosotros en cómo este nuevo Sistema Nacional de Salud se articula sobre un pronunciado protagonismo de las Comunidades Autónomas y sus correspondientes Servicios de Salud (arts. 49 a 55 de la LGS), hasta el punto de que son éstos básicamente los que, en su conjunto, constituyen el Sistema Nacional de Salud (art. 44.2). Tampoco interesa profundizar ahora en que ello supone, en beneficio de las Comunidades Autónomas, el desplazamiento y sustitución de las Corporaciones Locales en gran parte de sus funciones tradicionales (sobre todo, de las Diputaciones Provinciales), lo que se compensa parcialmente otorgándoles cierta participación en el control y en la gestión de específicos servicios sanitarios (arts. 55.2 y 56.3 de la LGS), sin perjuicio de mantener sobre la Administración local la carga de financiar los mismos servicios que ahora escapan a su competencia (art. 79 y disposición transitoria primera, punto 4).

Lo que si hay que destacar es que el nuevo Sistema Nacional de Salud se construye sobre la absorción de todos los medios sanitarios, ya estuvieron integrados originariamente en la Sanidad, en la Seguridad Social o en la Beneficencia, y ya fuese ésta estatal o local.

La Ley parte de la evidencia de que «en la actualidad este sistema sanitario de Seguridad Social está muy evolucionado, siendo gestor autónomo de una estructura sanitaria extendida por todo el territorio nacional, constituyendo la red sanitaria más

\footnotetext{
integra en el Ministerio de Sanidad y Consumo. Lo que se excluye es, precisamente, todo el campo de la Seguridad Social que nada tiene que ver con la protección de la salud. Así puede deducirse de la posterior estructuración del Ministerio de Sanidad y Consumo y del de Trabajo y. Seguridad Social. Asi, la Subsecretaría de sanidad, que sustituye a la anterior Secretaría de Estado, tiene las mismas competencias que ésta ostentaba (art. $3.1 \mathrm{del} \cdot$ Real Decreto 2967/1981, de 18 de diciembre); y el Ministerio de Sanidad y Consumo uasumirá las funciones de dirección, inspección y tutela del INSALUD (art. 5 del citado Real Decreto).
}

REVISTA DE ESTUDIOS. -8 
importante de nuestro país». (145). Sobre tan elemental constatación obvio es que el Sistema Nacional de Salud ha de incorporar a la sanidad tradicional toda esta red sanitaria, $y$, efectivamente, es ello una de las aportaciones sobresalientes de la LGS.

Igual ocurre con los distintos servicios de la Corporaciones Locales. El objetivo final, tal y como lo diseña el artículo 50.1 de la LGS, es que en los Servicios de Salud de cada Comunidad Autónoma se integran "todos los centros, servicios y establecimientos de la propia Comunidad, Diputación, Ayuntamiento y cualesquiera otras Administraciones territoriales intracomunitarias». Estos distintos Servicios de Salud, junto con los que permanezcan en manos de la Administración del Estado, constituirán el Sistema Nacional de Salud (art. 44.2).

La reciente aprobación de la Ley, el inacabado proceso de traspasos a las Comunidades Autónomas en materia de sanidad y Seguridad Social y la deliberada voluntad de introducir las reformas paulatinamente (146) no permiten todavía contemplar en su conjunto el panorama sanitario que la nueva Ley diseña. Así, la disposición adicional sexta establece que «los centros sanitarios de la Seguridad Social quedarán integrados en el Servicio de Salud, sólo en los casos en que la Comunidad Autónoma haya asumido competencias en materia de asistencia sanitaria de la Seguridad Social, de acuerdo con su Estatuto", mientras que, en caso contrario, sólo se prevén fórmulas de coordinación. Paralelamente, el INSALUD «continuará subsistiendo y ejerciendo las funciones que tiene atribuidas, en tanto no se haya culminado el proceso de transferencias a las Comunidades Autónomas con competencias en la materia» (disposición transitoria tercera, 1). Incluso se acepta como punto de partida que las "Comunidades Autónomas no cuentan con competencias suficientes en materia de sanidad para adoptar plenamente el funcionamiento de sus Servicios de Salud a lo establecido en la presente Ley», para cuya superación se establece únicamente la posibilidad de convenios con el Estado (disposición transitoria tercera, 3).

Todo ello, en lo que no podemos entrar aquí en detalle, supone una diversificación, según Comunidades Autónomas, de la articulación orgánica de la pretendida sanidad integral que no puede infravalorarse, pues afecta sustancialmente al sistema en su conjunto, entrañando todavía un enclave de asistencia sanitaria de la Seguridad Social separada. Incluso, cuando ello se supera, "los centros y establecimientos sanitarios que forman parte del patrimo-

(145) Preámbulo de la Ley, apartado I.

(146) La aplicación de la reforma que la Ley establece tiene, por fuerza, que ser paulatina, afirma el preámbulo de la Ley, apartado IV. 
nio único de la Seguridad Social continuarán titulados a nombre de la Tesorería General, sin perjuicio de su adscripción funcional» (Disposición adicional séptima).

También en lo que se refiere a los centros sanitarios de la Administración local, se prevé la posibilidad de que ésta conserve la titularidad, aunque con integración funcional al Servicio de Salud de la Comunidad Autónoma respectiva (art. 50.2 y Disposición Transitoria primera de la LGS).

Todo lo anterior matiza, sin duda, la efectividad real de la reforma; supone el reconocimiento de distintos grados de integración de los servicios sanitarios; presenta a la sanidad en un proceso de transformación aún inacabado que impide considerar su realidad actual como la cristalización del sistema previsto.

Pero, incluso así, se hace patente el abandono, ahora ya formal y a todos los efectos, de la idea de la sanidad pública como sanidad preventiva de tutela de la salud pública. La Administración sanitaria adopta hoy, en nuestro ordenamiento, el modelo de la sanidad integral, medio de realización del derecho a la protección de la salud. Ello implica que esta acción administrativa, que acotamos por su fin, abarca actualmente todas las cuestiones atinentes a la salud en su más amplio y moderno sentido y a ella incumbe la salud de la colectividad, la de los grupos específicos y la de los individuos, la de todos ellos, sin distinción por razón de renta o cualquier otro condicionamiento.

\section{IMPORTANCIA ACTUAL DE LA SANIDAD PREVENTIVA}

El concepto de sanidad integral, con el que hemos pretendido caracterizar las líneas maestras de nuestra Administración sanitaria, entraña superar el reducido campo de la sanidad preventiva, como hemos reiterado en las anteriores páginas. Incluso supone romper su aislamiento orgánico y funcional respecto de las restantes acciones públicas de incidencia sanitaria. Ello, sin embargo, no supone una superación y abandono de la misma finalidad clásica de la sanidad preventiva, ni de cierta peculiaridad de su instrumentación jurídica, ni de alguna especificidad de sus principios..., todo ello en el marco de una concepción de la sanidad más amplia.

Pero no se pretende únicameme situar y delimitar esta concreta acción administrativa. Se trata de la pervivencia de los caracteres propios de la sanidad liberal en este campo específico $y$, por lo pronto, con especial relevancia para nuestra perspectiva jurídica y nuestro objeto de estudio, de la misma idea de salud pública que mantiene sus diferencias respecto de otros bienes ahora tutelados 
por la sanidad y que transforma en parte a ésta, que adquiere un perfil distinto cuando se trata de proteger aquel bien.

Nos corresponde a nosotros comprobar tales extremos desde un punto de vista jurídico o, por mejor decir, comprobar cómo tal perspectiva ha sido y es adoptada por nuestro ordenamiento. Pero no parece ocioso subrayar que en el plano estrictamente sanitario las recientes tendencias a que ya hemos aludido y el mismo concepto de salud que se impone no desvirtúan en absoluto estas actuaciones sobre las condiciones sociales de salubridad, sino que, al contrario, destacan su importancia. La noción de salud como «estado completo de bienestar físico, mental y social» ha llevado a subrayar los factores sociales y ambientales. En tal sentido, se considera a la salud "como una armonía dinámica del hombre consigo mismo y con su medio» (147); que la salud depende "de la capacidad del organismo de mantener su medio interior en un medio exterior cambiante» (148); que "la enfermedad es el resultado de unas causas y unos condicionamientos ambientales de realización» (149); que la medicina debe estar "basada en la noción de adaptación del hombre a su ambiente» (150)...; consecuentemente con ello, la acción sanitaria debe operar no sólo sobre el individuo, sino también sobre el medio, las condiciones ambientales que hacen posible o favorecen su salud. Lo cierto es que, en este terreno, si algo puede caracterizar la evolución reciente es, precisamente, la extensión de la acción sanitaria a cuestiones y realidades que habían permanecido al margen (151).

\section{SANIDAD PREVENTIVA Y SALUD PUBLICA EN LA CONSTITUCION Y EN LA RECIENTE LEGISLACION SANITARIA}

Si desde un punto de vista estrictamente sanitario la nueva concepción de la sanidad integral no ha supuesto en modo alguno un abandono de los fines de lo que hemos denominado sanidad preventiva, sino que, al contrario, subraya su importancia en un contexto más amplio que el tradicional, igual ocurre, como no podía

(147) Informe Gremy-Pissaro-de Bernis, citado por P. LIGNEAN: "Quelle santé? Quelle prevention?» en el volumen colectivo dirigido por el mismo profesor La prévention Sanitaire en France, Paris, 1983, p. 3.

(148). C. BERNARD citado por LIGNEAN; Ibidem, p. 3.

(149) A. SERGIo SegarRA: Medicina preventiva y social, León, 1972, T. I, p. 56.

(150) Ibidem, loc. cit.

(151) No es de extrañar esta ampliación de la sanidad preventiva cuando para la OMS icon un sistema ordenado de saneamiento desaparecerían las tres cuartas partes de las enfermedades que asolan al mundo", citado por J. E. MARTÍNEZ JIMÉNEZ: Organización y reorganización..., op. cit., p. 723. 
ser de otra forma, en la introducción positiva que recientemente se ha realizado en nuestro ordenamiento.

Lo sustancial a nuestros efectos no es sólo la pervivencia de este aspecto de la sanidad y de las correspondientes funciones. Lo relevante es que, aun con la integración orgánica y funcional, este núcleo de la acción pública, dirigida a la protección de la salud pública, constituye algo más que el precedente del que se parte y en torno al cual se han desarrollado muy posteriormente actuaciones sanitarias de más amplias pretensiones. Presenta todavía hoy peculiaridades que, desde un punto de vista jurídico, le prestan caracteres diferenciadores del resto de la actividad sanitaria muy relevantes y que justifican, entendemos nosotros, su estudio separado.

Una muestra de ello es la subsistencia del término y del mismo concepto de salud pública. Configuramos antes la salud pública sobre la base y los presupuestos de la sanidad liberal. $Y$, efectivamente, la salud pública constituía un concepto instrumental para delimitar la sanidad liberal, al mismo tiempo que se asentaba sobre los postulados individualistas del sistema. Conforme a ello, parece que tal concepto había de ser incompatible con una sanidad a la que importan todas las cuestiones relativas a la salud, que rompe los límites a los que se había circunscrito; al menos, si no incompatible, el término de salud pública parece que había de convertirse en una noción convencional, sin verdadero trasfondo institucional y apenas justificable como criterio clasificatorio dentro de la amplitud general de la sanidad contemporánea. No ha sido así y no tenía por qué haber sido así, en realidad. Nos parece que no estamos sino ante una concreción de un fenómeno general propio de las transformaciones jurídicas que impone el Estado Social de Derecho. Este no niega los valores del Estado de Derecho tradicional, y en particular, los inherentes a la proclamación de la libertad. Consecuentemente, el Estado social necesita también de los instrumentos y conceptos técnicos acuñados anteriormente para ser, al mismo tiempo, Estado de Derecho. Uno de estos conceptos básicos del Estado de Derecho, y no sólo del Estado liberal de Derecho, es el orden público y, con él, uno de sus elementos integrantes, la salud o salubridad públicas. Estos constituyeron el esencial título habilitador de la Administración liberal, al menos en línea de principios, y especialmente para la imposición de limitaciones y deberes a los administrados, respaldadas eventualmente con la coacción. Evidente resulta que el Estado social justifica intervenciones de este género en base a bienes e intereses públicos distintos del orden público $y$, en este sentido, el concepto de orden público pierde operatividad. Específicamente lo hemos visto con 
referencia a uno de sus aspectos, la salud pública. Pero, además, el concepto de orden público justificaba en el Estado de Derecho determinada forma de actuación administrativa, cierta singularidad en la incidencia sobre el administrado, que ponía en cuestión la misma garantía de la libertad. Sólo ante este específico fin, relacionado con el orden público, se justificaba la peculiaridad propia de la llamada acción de policía. El Estado social, para ser al mismo tiempo Estado de Derecho, no puede prescindir de tales conceptos. Puede, y es esencial a él, aumentar los fines del Estado; puede, $y$ es lo normal, aumentar concretamente los fines que justifican las limitaciones administrativas a los ciudadanos. Pero las peculiaridades de la acción policial no pueden extenderse más allá de los límites que les reconoció el Estado de Derecho sin peligro para los caracteres esenciales de éste y para la misma libertad. La delimitación de este campo la aporta, la tiene que seguir aportando en el Estado social el concepto de orden público y con él, uno de sus elementos integrantes, la salud pública. No nos ocuparemos de ello con detalle. A nuestros efectos, suficiente es ahora comprobar la pervivencia formal del concepto de salud pública y de la referencia específica a la actividad administrativa dirigida a su protección.

a) En este punto especialmente destacable es que la misma Constitución se refiera de manera concreta a la salud pública y a la acción dirigida a su tutela. Así, el artículo 43.2 establece:

"Compete a los poderes públicos organizar y tutelar la salud pública a través de medidas preventivas y de las prestaciones y servicios necesarios. La Ley establecerá los derechos y deberes de todos al respecto.l

Señalamos ya anteriormente, la imprecisión y defectuosa redacción de este apartado, que, en principio, nos permitió reconocer como posible que aludiera únicamente a la sanidad preventiva. Interesa ahora subrayar que es ésa precisamente la interpretación más adecuada, aun dentro de la inseguridad de la que la desafortunada redacción del precepto no permite escapar.

Por lo pronto, se habla de "organizar y tutelar la salud pública». Si la salud pública es un bien, sea cual sea su contenido y expresión, cuya protección se encomienda a los poderes públicos, carece de sentido que éstos lo organicen; sólo puede pretenderse que lo tutelen. Cuando se dice «organizar la salud pública» se está entendiendo por ésta la sanidad pública, equívoco que, ya nos consta, no es inusual (152). Pero resulta aún más absurdo que se

(152) Vid. supra., epígrafe 4; en especial, nota 39. 
tutele a la sanidad pública $o$, incluso, afirmar que «compete a los Poderes públicos organizar...» la sanidad pública, pues resulta absolutamente evidente.

Carece igualmente de sentido afirmar, cuando se trata de proclamar un principio rector de política. social y económica, que "icompete a los poderes públicos....) la realización de determinada actividad o perseguir tal o cual fin. Es el único caso en que así se expresa el capítulo tercero del título I de la Constitución, que utiliza otras fórmulas más adecuadas a su sentido (los poderes públicos "asegurarán», "promoverán», «fomentarán», "velarán», "tutelarán», «garantizarán»...), que, desde luego, no es atribuir competencias ni reservar a los Poderes públicos determinadas actividades.

Tras esta deficiente redacción se esconde el diverso significado que al término "salud pública» otorgaban los distintos grupos de las Cortes Constituyentes $y$, en no escasa medida, la cuestión última de la asunción de la sanidad como servicio público o, incluso, de su socialización. Principalmente, señala Fernández Pastrana, los partidos de izquierda convirtieron la salud pública en equivalente a "sistema o régimen público de la sanidad» (153). Posteriormente, también parte de la doctrina ha atribuido tal sentido a la expresión constitucional (154). Por el contrario, Borrajo afirma que:

"«... Se hacia, y se hace, referencia a los poderes públicos en cuanto a sus competencias para la defensa y mejora de la salud colectiva... O, dicho de otro modo, la expresión "salud pública", tan cara a los partidos de izquierda, no logra alcanzar el sentido que estos parece que querían atribuirle, en sus enmiendas, de sistema o régimen público sanitario....) (155).

Es ésta la interpretación más correcta, según entendemos, no sólo porque es ése el significado tradicionalmente atribuido a la expresión "salud pública» (156), que además ha recogido el legislador postconstitucional (157), sino también porque es la que resulta más adecuada al resto de este polémico apartado 2 del artículo 43, como inmediatamente expondremos.

No es suficiente para descartar la interpretación de la expresión "salud pública» en su sentido propio el que inmediatamente se

(153) J. M. Fernández Pastrana: el servicio público..., op. cit., p. 27.

(154) Ibídem, pp. 27 y 28.

(155) E. BORRAJO DACRUZ: Comentario..., op. cit., p. 185.

(156) Sobre el concepto tradicional de salud pública, véase el apartado $D$, del epígrafe I de este capítulo. Su inclusión en la noción de orden público se analizará en el capítulo III.

(157) En particular nos referimos a la Ley Orgánica de Medidas Especiales para la Salud Pública que posteriormente analizaremos. 
precise que su tutela se realiza a través no sólo de medidas preventivas, sino también de «las prestaciones y servicios necesarios», como por algún autor se ha entendido (158), pues, a estas alturas, parece suficientemente claro que tales medidas son igualmente propias de la sanidad preventiva: asistencia y hospitalización de enfermos contagiosos, servicios de inspección, de vacunaciones, de sanidad animal, de sanidad exterior, análisis, etc.

Tampoco es determinante para excluir la interpretación que proponemos el que se señale que la ley establecerá no sólo deberes, sino también derechos. Al contrario, este último inciso del artículo 43.2 únicamente tiene sentido en una referencia a la sanidad preventiva.

En primer lugar, la referencia a la consagración legal de derechos adquiere pleno sentido en relación con las garantías del ciudadano frente a la acción administrativa de tutela de la salud pública consistente, con normalidad, en imposición de limitaciones intensas a los particulares, incluso afectando a los más elementales derechos. Piénsese en las hospitalizaciones forzosas, los aislamientos de enfermos o las vacunaciones obligatorias, por sólo señalar algunos ejemplos. El tema es lo suficientemente relevante para haber encontrado reflejo constitucional, como ocurre más claramente en Italia (159).

Sólo así puede entenderse que la Constitución imponga que los derechos se establezcan necesariamente en una ley. Por el contrario, si se entendiera que el artículo 43.2 de la Constitución se está refiriendo a derechos derivados de la genérica proclamación del derecho a la protección de la salud-derecho al establecimiento, acceso y prestaciones de los servicios sanitarios- la alusión a la ley parece inadecuada y contraria a la misma lógica constitucional. El mismo Fernández Pastrana, que entiende la mención de la salud pública como comprensiva de la Medicina asistencial y la alusión a derechos como los que legalmente se establezcan a las prestaciones sanitarias, considera, sin embargo, que uparece fuera de toda duda que nada impide la atribución de derechos por norma... reglamentaria». Y ello porque una interpretación restrictiva sería contraria al interés de los ciudadanos...» (160). Efectivamente así es y nada puede objetarse a tal argumentación que conduce a negar sentido a la reserva de ley establecida. Pero esto mismo es lo que hace más viable otra interpretación que reconduzca los derechos a

(158) Así J: M. Fernández PASTRANA: El servicio público..., op. cit.,p. 27.

(159) Así, el artículo 33.2 de la Constitución italiana dice: «No puede ọbligarse a nadie a un determinado tratamiento sanitario sino por disposición de la ley, la que en ningún caso pođrá violar los límites impuestos por el respeto de la persona humana». Evidentemente, podria entenderse que nuestra Constitución afronta idéntica cuestión en el artículo 43.2.

(160) J. M. FERNÁNDEZ PASTRANA: El servicio público.... op. cit., p. 76. 
los que el artículo se refiere, no a los servicios públicos de asistencia sanitaria, sino a la idea de derechos inviolables en la actuación administrativa de tutela de la salud pública, a la de límites a tal actuación. La Constitución habría querido así subrayar la superioridad de ciertos bienes respecto de la salud, en la misma línea que la Constitución italiana lo hace al afirmar el respeto a la persona como límite a la actuación sanitaria. De esta forma, más que una reserva de ley, hay un mandato al legislador para que establezca estos derechos que limiten la acción administrativa de tutela de la salud pública. Ciertamente serán proyección de los derechos fundamentales y libertades públicas constitucionalizados, pero proyecciones requeridas en este sector concreto tan propenso a sacrificar los valores individuales y en el que el principio salus populi suprema lex esto encuentra tan fácil aplicación.

Además, y en cualquier caso, también es posible hablar de derechos a la acción propia de la sanidad preventiva. Así, por ejemplo, a la asistencia sanitaria propia de ésta, es decir, a la asistencia profiláctica. Tradicionalmente no se han configurado en este terreno verdaderos derechos del enfermo a tal asistencia, que, más bien, se establecía como un deber de aquél para evitar poner en riesgo la salud de la población. Pero nada se opone a la posibilidad de reconocimiento de un tal derecho a favor de los aquejados de estas enfermedades socialmente relevantes, sin que ello alterase su naturaleza de medida sanitaria preventiva. En tal sentido, afirma Escribano Collado que la prestación de asistencia profiláctica puede articularse «reconociéndosele al individuo afectado el derecho a obtener los cuidados de todo tipo necesarios para recobrar la salud, así como la facultad de las autoridades de imponer coactivamente un régimen sanitario tendente a proteger la salud colectiva» (161). No creemos que sea esto lo que establece la Constitución, ni tendría sentido que se recogiera en ésta un aspecto tan concreto $y$, por así decirlo, menor. Pero es suficiente para demostrar que la referencia a derechos no supone forzosamente que el artículo 43.2 esté consagrando algo más que lo propio y característico de la sanidad preventiva: la tutela de la salud pública.

Sí que es posible, en cambio, que también en este campo haya querido la Constitución reforzar la situación de los ciudadanos mediante la determinación legal de derechos a la acción preventiva de la Administración, disminuyendo la inicial libertad de ésta. Este es el sentido que Borrajo Dacruz confiere al establecimiento de derechos que prevé el artículo 43.2 de la Constitución:

(161) P. Escribano Collado: El derecho..., op. cit., p. 22. 
«El derecho subjetivo reaccional, que permite al ciudadano exigir de la Administración, y en su caso de los otros ciudadanos, la conducta establecida en la ley para la garantía del bien colectivo, es el derecho que se añadió a los deberes en la nueva redacción del artículo 43.2 de la Constitución. Es decir, los derechos contemplados son los que están conectados a las garantías de la salud colectiva, y de ahí su carácter reflejo e indirecto, no de derechos subjetivos perfectos...) (162).

Esta interpretación, que remite a la construcción de García de Enterría del derecho reaccional, no parece sostenible en su totalidad: si la Constitución dice que la ley establecerá derechos, éstos no podrán ser derechos reaccionales a los que, precisamente, hay que acudir cuando la ley establece normas de acción de la Administración, sin consagrar con ello derechos de los administrados a que se actúe en la forma predeterminada. Si la ley consagra derechos de los ciudadanos a que la Administración actúe en determinado sentido, no cabe dar entrada a la figura de los derechos reaccionales. Si, por el contrario, lo que la Constitución quisiera es que la ley reconociera derechos reaccionales a la acción sanitaria preventiva, lo que la ley debería hacer es precisamente no reconocer ningún derecho, sino simplemente regular tal actuación administrativa, conduciendo, en definitiva, al absurdo este último inciso del artículo 43.2. Es posible admitir, sin embargo, esta misma interpretación prescindiendo de la idea de los derechos reaccionales para entender, simplemente, que la ley habrá de consagrar verdaderos derechos subjetivos de los ciudadanos a determinadas acciones de tutela de la salud pública o al establecimiento de determinados servicios de carácter preventivo.

No lo ha entendido así el legislador, que ni en la Ley General de Sanidad, ni en la Orgánica de Medidas Especiales en Materia de Salud Pública ha establecido tales derechos. No es ello, sin embargo, absolutamente desconocido en nuestro Derecho en relación con los aspectos relacionados con la salud pública. Así, el artículo 26.1 de la Ley 7/1985, de 2 de abril, Reguladora de las Bases del Régimen Local, establece, entre otros, determinados servicios de tutela de la salud pública que obligatoriamente deberán prestar los municipios, como recogida de residuos, limpieza viaria, control de alimentos y bebidas o protección del medio ambiente. A esta imposición ya tradicional (obligaciones municipales mínimas) se suma la novedad, muy relevante, de incluir entre los derechos de los vecinos el de "exigir la prestación y, en su caso, el estableci-

(162) E. Borrajo DaCruz, Comentarios..., op. cit., p. 187 
miento del correspondiente servicio público, en el supuesto de constituir una competencia municipal propia de carácter obligatorio» (art. 18.1.g de la Ley Reguladora de las Bases del Régimen Local).

Aún así, no parece que la Constitución se estuviese refiriendo a la consagración legal de «derechos a la acción de la sanidad preventiva»: ni tendría sentido reservar ello a la ley, ni parece que la figura del derecho subjetivo case bien con la protección de un bien esencialmente supraindividual como es la salud pública.

Se trata, reiterémoslo, de derechos frente a esta acción administrativa. Así adquiere sentido la conjunta referencia a «los derechos y deberes de todos al respecto", límites positivos y negativos de las potestades administrativas especialmente incisivas que en la tutela de la salud pública se ejercitan. La Constitución, pues, percibe y refleja la singularidad de la sanidad preventiva, al referirse específicamente a la tutela de la salud pública. Es muy posible que ello fuera innecesario, pero, en cualquier caso, no creemos que sea superfluo cuando de demostrar la pervivencia y singularidad de esta acción administrativa en el marco general de la sanidad se trata.

En suma, la tutela de la salud pública aparece en la Constitución como una de las manifestaciones del denominado "derecho a la protección de la salud». No parece necesario insistir ahora en que ni en este artículo ni en los restantes preceptos que recogen «los principios rectores de política social y económica» se reconocen verdaderamente derechos, pese a su tenor literal. Se trata, como es hoy admitido por nuestra doctrina, de determinaciones de fines del Estado, de imposición de deberes a los Poderes públicos.

Sí importa destacar, como consecuencia de lo expuesto, que el derecho a la protección de la salud, expresión más correcta que la del derecho a la salud (163), no se traduce, como es habitual considerar respecto a los denominados derechos sociales y los "principios rectores de política social y económica», en servicios públicos y en prestaciones positivas para los ciudadanos. Al menos no es esa su única consecuencia. El artículo 43.2 que analizamos es buena muestra de ello al prever concretamente la imposición de deberes. Y es que la sanidad preventiva exige predominantemente, aunque no únicamente, medidas de limitación de las actividades de los particulares. No es, desde luego, el único supuesto en que así ocurre (164), ni puede convertirse este tipo de acciones administrativas en las únicas que pretendan hacer efectivo el derecho a la

(163) Sobre este extremo, vid., E. BORRAJO DACRUZ, en Comentarios..., op. cit., pp. 173 a 175 .

(164) Asi, por ejemplo, los artículos 45 y 46 de la Constitución prevén medidas represivas como forma de hacer efectivos los principios de política social y económica que consagran. 
protección de la salud. Pero, en cualquier caso, queda patente que estos "principios rectores de política social y económica» suponen también directamente acciones de incidencia negativa en la situación de los ciudadanos. En este punto forzoso es señalar que la salud pública es también un límite a los derechos de los ciudadanos, y como tal es configurada positivamente tanto en nuestro Derecho como en los Textos internacionales básicos sobre derechos humanos (165).

b) La reciente legislación sanitaria española, que, como ya pusimos de relieve, se basa en la pretensión de una sanidad integral, pone de manifiesto la importancia actual de las tradicionales funciones de la sanidad preventiva y la pervivencia de su peculiaridad, aun dentro de un campo de acciones administrativas mucho más amplio, en el que se integra orgánica y funcionalmente.

Comencemos por destacar que, pese a que éstos son los aspectos más clásicos de la sanidad y en los que el legislador introducía menos novedades en el conjunto de una reforma de gran alcance, las dos recientes Leyes sanitarias prestan atención y patentizan la relevancia conferida a los aspectos de tutela de la salud pública, esto es, a la acción de la sanidad preventiva.

Según el artículo $3 .^{\circ}$ de la Ley General de Sanidad, «los medios y actuaciones del sistema sanitario estarán orientados prioritariamente... a la prevención de las enfermedadesı, $y$, aun cuando en el contexto general de la ley quede claro que esta uprevención de las enfermedades» incluye la individual, lo que siempre resulta evidente es que abarca a la sanidad preventiva propiamente dicha, es decir, a la tutela de la salud pública, que es esencialmente el medio más idóneo y clásico de prevención de las enfermedades. En suma, afirmar como prioritaria la prevención de las enfermedades es necesariamente conferir valor destacado a la acción de protección de la salud pública. Igual puede deducirse de la consideración de la «prevención de las enfermedades y no sólo de la curación de las mismas" como fin al que se orientan las actuaciones de la Administración sanitaria que efectúa el artículo $6 .^{\circ}$ de la ley.

A mayor abundamiento, y más explícitamente en lo que al protagonismo de este concreto campo de la sanidad se refiere, el artículo 19 proclama:

«1. Los poderes públicos prestarán especial atención a la sanidad ambiental, que deberá tener la correspondiente consideración en los programas de salud.»

(165) Sobre este extremo resultan suficientemente ilustrativos, por lo que a la doctrina española se refiere, los estudios de E. COBREROS MENDAZONA: «Notas acerca de los requisitos jurídicos de un eventual tratamiento sanitario obligatorio (a propósito de los enfermos del 
Tal sanidad ambiental -algunos de cuyos aspectos más destacables son enumerados en el párrafo 2 del mismo artículo- remite, en definitiva, a ciertas condiciones del medio físico, natural y social (166) que hacen posible 0 , incluso, favorecen la salud; esto es, la sanidad ambiental es la acción dirigida a conservar o restaurar las condiciones de salubridad del ambiente $y$, consecuentemente, una vertiente destacadísima de la tutela de la salud pública, de la sanidad preventiva. Así pues, a ésta, a un aspecto de ésta, los poderes públicos deben prestar especial atención. En la misma línea, el artículo $8 .^{\circ}$. 1 , de la Ley General de Sanidad considera "actividad fundamental del sistema sanitario» lo relativo a los estudios epidemiológicos, y el apartado 2 del mismo artículo califica como "actividad básica (167) del sistema sanitario la que pueda incidir sobre el ámbito propio de la veterinaria de salud pública...».

$Y$, efectivamente, al enumerarse en el artículo 18 de la Ley General de Sanidad las distintas actuaciones de los Servicios de Salud, las propias características de la sanidad preventiva ocupan un papel destacado: "La promoción y mejora de los sistemas de saneamiento, abastecimiento de aguas, eliminación y tratamiento de residuos líquidos y sólidos; la promoción y mejora de los sistemas de saneamiento y control del aire, con especial atención a la contaminación atmosférica; la vigilancia sanitaria y adecuación a la salud del medio ambiente en todos los ámbitos de la vida, incluyendo la vivienda» (apartado 6); "El control sanitario y la prevención de los riesgos para la salud derivados de los productos alimentarios...» (apartado 10); «El control sanitario de los productos farmacéuticos...» (apartado 11); "Promoción y mejora de las actividades de veterinaria de salud pública, sobre todo en las áreas de la higiene alimentaria, en mataderos e industrias de su competencia, y en la armonización funcional que exige la prevención y la lucha contra la zoonosis» (apartado 12)...

No sólo se trata de que se recojan, incluso destacándose su importancia, los fines, actuaciones y campos propios de la sanidad

SIDA)", en REDA, núm. 57, pp. 59 y ss., y de J. L. BELTRÁN AGUIRRE: "Ĺa incidencia de la actividad administrativa sanitaria en los derechos y libertades fundamentales de las personas", en Revista Vasca de Administración Pública, núm. 6, pp. 155 y ss.

(166) Sobre medio ambiente, medio social y su relación con la salud, vid., C. MAESTRE ROSI: El sistema sanitario y la salud. Barcelona, 1982, pp. 8 a 12.

(167). La expresión uactividad básica» es equívoca pues podría entenderse en el sentido de incluida en las Bases de la sanidad del artículo 149.1.16. ${ }^{a}$. Creemos, sin embargo, que el legislador en este artículo sólo pretendia destacar su carácter fundamental y ello por varias razones: a) Es eso lo que hace el apartado 1 del mismo artículo respecto de otra actividad y no parece pensable que el apartado 2 pretendiera algo distinto; b) Está incluido entre los «principios generales" y existe un título específico de la Ley dedicado a la distribución de competencias; $c$ ) Existen otras actividades que podrían incluirse según la LGS en las bases de la sanidad (art. 40) y no tendría sentido que aisladamente se hiciera referencia a una sola de ellas. 
preventiva. La peculiaridad que domina, aunque no en toda su extensión ni caracterizándola en su totalidad, la acción administrativa que en su seno puede desarrollarse sale también a flote sobre la base de aislar como un fin específico la protección de la salud pública y de considerar a ésta un bien distinto de la salud individual que determina o posibilita actuaciones administrativas diferenciadas. Suficiente es ahora constatar que la salud pública y su tutela aparecen en la legislación como un bien y una acción administrativa formalmente diferenciados, sin entrar aún en las razones de fondo que lo justifican.

Actualmente, la expresión más rotunda de ello la constituye la Ley Orgánica 3/1986, de 14 de abril, precisamente denominada de "Medidas Especiales en Materia de Salud Pública». La razón de ser de esta ley, separada de la LGS, no es más, según ya avanzamos, que la de haberse considerado las medidas en ella previstas incluidas en la reserva de la Ley Orgánica del artículo 81 de la Constitución por su incidencia directa en los derechos fundamentales y libertades públicas. Revela ello que sólo la salud pública se ha considerado un bien suficiente para adoptar las drásticas medidas limitativas allí previstas. Así se desprende con claridad en su artículo 1: sólo podrán adoptarse ual objeto de proteger la salud pública...». Como sinónimo de esta expresión se habla también de "salud de la población» (art. 2). Ello no quiere decir, de ninguna forma, que se concentren en ella todas las acciones defensivas de la salud pública. Las que por su contenido no queden afectadas por la reserva de la Ley Orgánica se contienen en la LGS, aunque su finalidad sea, exactamente igual, la tutela de la salud pública. Así se comprueba al estudiar el iter parlamentario de estas leyes (168).

De hecho, en la LGS la "salud pública» aparece como un límite a la libre opción del enfermo y a la necesidad de consentimiento para someterse a intervenciones médicas (art. 10.6.a); como criterio para determinar las infracciones y su gravedad (art.

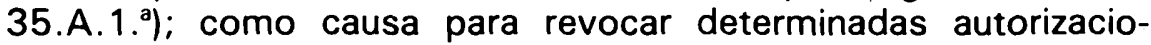
nes (art. 96.2)... Pero es especialmente el capítulo quinto del título I (arts. 23 y siguientes) el que aborda con carácter general las medidas de «intervención» en defensa de la salud pública: creación de registros públicos (art. 23), sometimiento a «limitaciones preventivas» (art. 24), sometimiento a inscripciones o autorizaciones, establecimiento general de requisitos mínimos, intervención administrativa (art. 25), control de la publicidad (art. 27), suspensión

(168) El Proyecto de Ley General de Sanidad aprobado por el Gobierno (publicado en el «Boletin Oficial de las Cortes Generales, Congreso de los Diputados», Serie A, 23 de abril de 1985, núm. 145-1) contenía también en sus artículos 21,22 y 29 lo que posteriormente paś a constituir una Ley distinta y ya expresamente se les atribuía el carácter de Ley Orgánica en la Disposición adicional sexta del referido Proyecto. 
provisional, prohibición de actividades, clausura definitiva de establecimientos (art. 31.2), etc. El bien protegido es la salud pública. Así se desprende de la utilización de términos que deben entenderse como equivalentes: "salud de los ciudadanos» y usalud colectiva», indistintamente en el artículo 25.3; "salud de la población», en el artículo 29.3; "salud colectiva», en el artículo 31.2... En algunos preceptos se habla sólo de la salud, sin adjetivarla (arts. 24 ó 26); además, el capítulo aparece bajo el equívoco epígrafe «De la intervención pública en relación con la salud individual y colectiva». Pese a todo, el conjunto de los preceptos en él contenidos, las referencias reiteradas en ellos a la "salud colectiva» o "de la población» permiten concluir sin dudas que se trata de medidas preventivas de tutela de la salud pública. Corrobora esta interpretación el hecho de que era en este capítulo del proyecto de Ley en el que se incluian las que posteriormente el legislador ha considerado "medidas especiales en materia de salud pública» (Ley Orgánica 3/1986, de 14 de abril). Más aún: en el proyecto de Ley General de Sanidad, el capítulo quinto, que ya se denominaba "De la intervención en relación con la salud individual y colectiva», se iniciaba con un artículo 21 que proclamaba con claridad que las medidas en este capítulo sólo se podían adoptar para proteger la salud pública (169). Aunque posteriormente se cambió la colocación de este artículo (170), parece evidente que expresaba con claridad con qué sentido se hablaba de la salud en todos los demás preceptos del capítulo y cuál era la finalidad única con que podían adoptarse las medidas en él previstas. Nada de ello se modificó realmente, aunque no luzca ahora expresamente.

Lo hasta aquí expuesto tiene consecuencias, tanto jurídicas como estrictamente sanitarias, muy relevantes. Nuestro propósito, sin embargo, queda cumplido tras haber expuesto las anteriores bases. Aún así, queremos señalar que sobre ellas se asienta una de las principales aportaciones de la reciente legislación sanitaria española; quizás menos destacada socialmente que las ampliacio-

(169) El artículo 21 del Proyecto decia: «A los efectos de proteger la salud pública y prevenir los peligros para la misma, las autoridades sanitarias... podrán... adoptar las medidas previstas en el presente capitulo...) Volveremos posteriormente sobre él para poner de manifiesto que la sanidad sóio puede adoptar las medidas legalmente previstas de manera expresa. Ahora sólo nos interesa subrayar que todas las medidas están establecidas exclusivamente para la defensa de la salud pública.

(170) Por el carácter de Ley Orgánica que le atribuía la Dispósición adicional sexta del Proyecto de LGS, se incluyó finalmente como artículo 1. de la Ley Orgánica 3/1986 con modificación de redacción mínimas. En realidad tal artículo sólo tenía carácter orgánico por su relación con determinadas medidas previstas en el capitulo que podian incluirse en la reserva del artículo 81 de la Constitución, pero no en relación con las restantes previsiones del capitulo a las que también afectaba. Cuando el legislador optó por hacer una Ley Orgánica y otra ordinaria, deberia de haber incluido en aquélla y en el capítulo $V$ del título I de ésta una cláusula general equivalente a la analizada. 
nes de la sanidad asistencial o que la extensión a la promoción y educación sanitarias, pero no menos importante. Se asienta una ingente acción administrativa de tutela de la salud pública tradicionalmente asumida con mayor o menor amplitud, pero que ahora, conservando su singularidad, se adecúa, como nunca lo había estado en España, a los postulados y exigencias del Estado de Derecho. Singularidad, efectivamente, porque la protección frente a las perturbaciones individuales de la salud pública sigue justificando que la sanidad preventiva ostente las más intensas potestades de. limitación sobre los ciudadanos, incluso sobre sus derechos fundamentales, como se encarga de demostrar sobradamente la Ley. Orgánica 3/1986. Singularidad también porque la salud pública, en su sentido estricto y propio, justifica tan amplias habilitaciones legales a potestades limitativas de la libertad individual. Pero todo ello con adecuación a las exigencias del Estado de Derecho y a las garantías de los ciudadanos para que sus derechos no sean inmolados inútilmente. Así, por primera vez, la Administración sanitaria encuentra prefigurados legalmente sus poderes, necesariamente amplios, pero tasados, mensurables, conforme a una ley y no un sinfín de disposiciones reglamentarias sin más base que un supuesto poder natural y omnímodo de policía. Así, se contienen también reiteradas alusiones en las dos leyes de 1986 al carácter exclusivamente defensivo de las medidas a adoptar y a su obligatoria restricción a lo que sea imprescindible para garantizar la salud pública. Así, finalmente, el acertado artículo 28 de la LGS proclama expresamente los principios de "proporcionalidad" y favor libertatis que han de situar a la Administración sanitaria en el justo equilibrio entre la eficacia en la consecución del interés público y el respeto a los derechos individuales.

Sin desarrollar ahora todo esto, que nos llevaría a un examen pormenorizado de esas potestades y de sus límites generales, imposible de realizar aquí, sí cabe afirmar, aun aceptando el clásico término de "policía sanitaria», que la actuai legislación española configura unna "policía sanitaria del Estado de Derecho». 